\title{
KCC2 Chloride Transport Contributes to the Termination of Ictal Epileptiform Activity
}

\author{
Volodymyr I. Dzhala, ${ }^{1,2}$ and ${ }^{-K e v i n ~ J . ~ S t a l e y ~}{ }^{1,2}$
}

https://doi.org/10.1523/ENEURO.0208-20.2020

${ }^{1}$ Department of Neurology, Massachusetts General Hospital, Boston, MA 02114 and ${ }^{2}$ Harvard Medical School, Boston, MA 02114

\section{Visual Abstract}
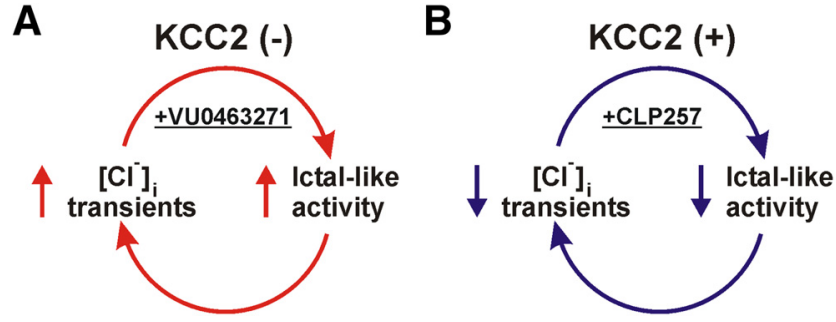

Recurrent seizures intensely activate $G A B A_{A}$ receptors $\left(G A B A_{A}-R s\right)$, which induces transient neuronal chloride $\left(\left[\mathrm{Cl}^{-}\right]_{\mathrm{i}}\right)$ elevations and depolarizing GABA responses that contribute to the failure of inhibition that engenders further seizures and anticonvulsant resistance. The $\mathrm{K}^{+}-\mathrm{Cl}^{-}$cotransporter $\mathrm{KCC} 2$ is responsible for $\mathrm{Cl}^{-}$extrusion and restoration of $\left[\mathrm{Cl}^{-}\right]_{\mathrm{i}}$ equilibrium $\left(\mathrm{E}_{\mathrm{Cl}}\right)$ after synaptic activity, but at the cost of increased extracellular potassium which may retard $\mathrm{K}^{+}-\mathrm{Cl}^{-}$extrusion, depolarize neurons, and potentiate seizures. Thus, KCC2 may either diminish or facilitate seizure activity, and both proconvulsant and anticonvulsant effects of KCC2 inhibition have been reported. It is now necessary to identify the loci of these divergent responses by assaying both the electrographic effects and the ionic effects of KCC2 manipulation. We therefore determined the net effects of KCC2 transport activity on cytoplasmic chloride elevation and $\mathrm{Cl}^{-}$extrusion rates during spontaneous recurrent ictal-like epileptiform discharges (ILDs) in organotypic hippocampal slices in vitro, as well as the correlation between ionic and electrographic effects. We found that the KCC2 antagonist VU0463271 reduced $\mathrm{Cl}^{-}$ extrusion rates, increased ictal $\left.\mathrm{CCl}^{-}\right]_{\mathrm{i}}$ elevation, increased ILD duration, and induced status epilepticus (SE). In contrast, the putative KCC2 upregulator CLP257 improved chloride homeostasis and reduced the duration and frequency of ILDs in a concentration-dependent manner. Our results demonstrate that measuring both the ionic and electrographic effects of KCC2 transport clarify the impact of KCC2 modulation in specific models of epileptiform activity. Anticonvulsant effects predominate when KCC2-mediated chloride transport rather

\section{Significance Statement}

In an in vitro preparation that generates spontaneous ictal-like epileptiform discharges (ILDs), we measured the effects of acute KCC2 modulation on both neuronal chloride and ILD activity. We demonstrate that inhibiting KCC2 enhances ictal elevations in $\left.\mathrm{Cl}^{-}\right]$, reduces extrusion and prolongs ILDs. Enhancing KCC2 activity reduces ictal $\left[\mathrm{Cl}^{-}\right]_{\mathrm{i}}$ elevations and ILD duration. These findings regarding the role of $\mathrm{KCC} 2$ on baseline chloride, chloride elevations during ILD activity, $\mathrm{Cl}^{-}$extrusion rates and ILD activity resolve conflicting reports in the literature, provide a coherent understanding of the role KCC2 activity in chloride homeostasis during ILDs, and support the feasibility of developing KCC2 modulators into sorely-needed anticonvulsant medications. 
than potassium buffering is the rate-limiting step in restoring $E_{\mathrm{Cl}}$ and the efficacy of GABAergic inhibition during recurrent ILDs.

Key words: chloride; CLP257; GABA; KCC2; seizure; VU0463271

\section{Introduction}

Recurrent seizures often respond poorly to first line medications that target the inhibitory chloride-permeable $\mathrm{GABA}_{\mathrm{A}}$ receptor (GABA $A_{A}-R$; Painter et al., 1999; Fung et al., 2019). Low intracellular chloride concentration $\left(\left[\mathrm{Cl}^{-}\right]_{i}\right)$ is an important determinant of inhibitory postsynaptic $\mathrm{GABA}_{\mathrm{A}}-\mathrm{R}$ signaling. This low $\left.\mathrm{Cl}^{-}\right]_{\mathrm{i}}$ is established by a Gibbs-Donnan system comprised of impermeant cytoplasmic and extracellular anions, and a membrane permeability for chloride salts and water provided by equilibrative cation-chloride cotransporters (CCCs; Delpire and Staley, 2014; Glykys et al., 2014). This type of system can be characterized by the reversal potential for membrane chloride currents $\left(E_{C l}\right)$ when the system is at equilibrium. $\mathrm{GABA}_{\mathrm{A}}-\mathrm{R}$-gated chloride currents alter the local $\left[\mathrm{Cl}^{-}\right]_{\mathrm{i}}$ and move this system away from equilibrium. Restoration of equilibrium after synaptic signaling is achieved by the flux of chloride salts through the CCCs, such as the $\mathrm{K}^{+}-\mathrm{Cl}^{-}$cotransporter $\mathrm{KCC} 2$ (transporting $1 \mathrm{~K}^{+}$ and $1 \mathrm{Cl}^{-}$ion per cycle) and $\mathrm{Na}^{+}-\mathrm{K}^{+}-2 \mathrm{Cl}^{-}$cotransporter 1 (NKCC1; transporting $1 \mathrm{Na}^{+}, 1 \mathrm{~K}^{+}$, and $2 \mathrm{Cl}^{-}$ions per cycle; Gamba, 2005). Because $\mathrm{GABA}_{\mathrm{A}}$-gated chloride currents are "downhill," that is, the chloride diffuses along its electrochemical gradient, the restoration of the baseline $\left[\mathrm{Cl}^{-}\right]_{i}$ requires energy; this is applied via cation cotransport. For $\mathrm{KCC} 2$, forward transport (canonical $\mathrm{Cl}^{-}$extrusion) is driven by downhill potassium extrusion that increases extracellular potassium $\left(\left[\mathrm{K}^{+}\right]_{0}\right)$. For NKCC1, forward transport (canonical $\mathrm{Cl}^{-}$import) is driven by downhill sodium import that increases intracellular sodium. The restoration of $\mathrm{K}^{+}$and $\mathrm{Na}^{+}$ gradients ultimately requires energy in the form of ATP as $\mathrm{Na}^{+}-\mathrm{K}^{+}$-ATPase-mediated cation transport that restores the $\mathrm{Na}^{+}$and $\mathrm{K}^{+}$gradients.

High rates of synaptic $\mathrm{Cl}^{-}$influx, as occurs during seizures, stresses neuronal $\mathrm{Cl}^{-}$homeostasis (Staley and Proctor, 1999). To restore $\left[\mathrm{Cl}^{-}\right]_{\mathrm{i}}$ to baseline, high rates of CCC-mediated $\mathrm{Cl}^{-}$efflux are required. But at these high cotransport rates, $\mathrm{K}^{+}$efflux is also increased, which may elevate $\left[\mathrm{K}^{+}\right]_{0}$ (Viitanen et al., 2010). This may change the equilibrium conditions for CCC transport, leading to higher $\left[\mathrm{Cl}^{-}\right]_{\mathrm{i}}$. In turn, this may lead to proconvulsant depolarizing

Received May 19, 2020; accepted November 3, 2020; First published November 25, 2020.

The authors declare no competing financial interests.

Author contributions: V.I.D. and K.J.S. designed research; V.I.D. performed research and analyzed data; V.I.D. and K.J.S. wrote the paper.

This study was supported by the United States of America National Institutes of Health and National Institute of Neurological Disorders and Stroke grant R01 NS040109 (K.J.S.).

Acknowledgements: We thank Michelle Mail for technical assistance.

Correspondence should be addressed to Volodymyr I. Dzhala at vdzhala@ mhg.harvard.edu or Kevin J. Staley at staley.kevin@mgh.harvard.edu.

https://doi.org/10.1523/ENEURO.0208-20.2020

Copyright (C) 2021 Dzhala and Staley

This is an open-access article distributed under the terms of the Creative Commons Attribution 4.0 International license, which permits unrestricted use, distribution and reproduction in any medium provided that the original work is properly attributed.
GABA conductance, while the elevated $\left[\mathrm{K}^{+}\right]_{0}$ may depolarize neurons directly, predisposing to further seizures (González et al., 2015). Given these secondary effects of CCCs, it may not be surprising that there are conflicting results regarding the role of CCCs in seizures. When in vitro epileptiform activity was induced with 4-AP, blocking KCC2 transport activity with either VU0240551 or high doses of bumetanide abolished ictal-like epileptiform discharges (ILDs), while enhancing KCC2 activity with a high concentration of CLP257 increased the duration of ILDs (Hamidi and Avoli, 2015). On the other hand, there are both genetic and pharmacological data supporting an anticonvulsant role of KCC2 expression in chronic temporal lobe epilepsy. For example, selective inhibition of KCC2 with VU0463271 led to hyperexcitability and epileptiform discharges in hippocampal slices in vitro exposed to low magnesium, and induced seizures in vivo (Sivakumaran et al., 2015). Human loss of function mutations of KCC2 result in febrile seizures or more severe early infantile epileptic encephalopathies (Kahle et al., 2016; Duy et al., 2019). Experimental studies of gain of function mutations in KCC2 have reported resistance to 4-AP induced ILDs, lower baseline $\left[\mathrm{Cl}^{-}\right]_{\text {, }}$, and higher $\mathrm{Cl}^{-}$extrusion rates after exposure to glutamate (Moore et al., 2018). However, since glutamate massively increases $\left[\mathrm{K}^{+}\right]_{0}$ (Vargova et al., 2001) creating a proportionate increase in equilibrium $\left[\mathrm{Cl}^{-}\right]_{\mathrm{i}}$, increased $\mathrm{KCC} 2$ activity would only alter $\mathrm{Cl}^{-}$extrusion in recorded cells that were not in areas of high $\left[\mathrm{K}^{+}\right]_{0}$; how this relates to ictal conditions (Heinemann et al., 1977) is therefore unclear (Lux and Heinemann, 1978).

Here, we studied KCC2 transport activity during recurrent ILDs in an in vitro model of epileptogenesis that does not require exogenous convulsant conditions (Berdichevsky et al., 2012) and in which both $\left[\mathrm{Cl}^{-}\right]_{\mathrm{i}}$ and electrographic epileptiform activity could be monitored. We describe the effects of ILDs on $\left[\mathrm{Cl}^{-}\right]_{\mathrm{i}}$. We measured the effects of the low and high affinity KCC2 inhibitors furosemide and VU463271 (Delpire et al., 2012), as well as the putative KCC2 activator CLP257 (Gagnon et al., 2013; Cardarelli et al., 2017) on epileptiform activity as well as neuronal chloride elevation and extrusion rates during spontaneous ILDs.

\section{Materials and Methods}

All animal-use protocols were in accordance with the guidelines of the National Institutes of Health and the Massachusetts General Hospital Center for Comparative Medicine on the use of laboratory animals. All protocols were approved by the Subcommittee on Research and Animal Care (SRAC).

\section{Culture of organotypic hippocampal slices and experimental conditions}

Transverse $350-\mu \mathrm{m}$ hippocampal slices were prepared from C57BL/6 and CLM1 (Duke University Medical Center, Durham, NC) mice at postnatal day (P)6-P7 as previously 
described (Dyhrfjeld-Johnsen et al., 2010; Berdichevsky et al., 2012). Acute slices were mounted on poly-L-Lysine coated glass coverslips (Electron Microscopy Sciences). Slices were incubated in $1000 \mu \mathrm{l}$ of NeuroBasal/B27(1×) medium (Invitrogen by Life Technologies) supplemented with $0.5 \mathrm{~mm}$ GlutaMAX and $30 \mu \mathrm{g} / \mathrm{ml}$ gentamicin (all from Invitrogen) in six-well plates with low-evaporation lid (Becton Dickinson Labware), in a humidified $37^{\circ} \mathrm{C}$ atmosphere that contained $5 \% \mathrm{CO}_{2}$, placed on a rocking platform (less than one cycle per minute). Culture medium was changed bi-weekly. For acute recordings and imaging, slices were transferred to a submerged chamber and continuously superfused in oxygenated $\left(95 \% \mathrm{O}_{2}\right.$ and $\left.5 \% \mathrm{CO}_{2}\right)$ artificial CSF (ACSF) containing the following: $126 \mathrm{~mm} \mathrm{NaCl}$, $3.5 \mathrm{~mm} \mathrm{KCl}, 2 \mathrm{~mm} \mathrm{CaCl}_{2}, 1.3 \mathrm{~mm} \mathrm{MgCl}, 25 \mathrm{~mm} \mathrm{NaHCO}_{3}, 1.2$ $\mathrm{mm} \mathrm{NaHPO}$, and $11 \mathrm{~mm}$ glucose $(\mathrm{pH} 7.4)$ at $32 \pm 0.5^{\circ} \mathrm{C}$ and a flow rate of $2 \mathrm{ml} / \mathrm{min}$. All organotypic hippocampal slices were used at days in vitro (DIV)1-DIV28.

Pharmacological agents included the Bumetanide at a concentration $(200 \mu \mathrm{M})$ that blocks NKCC1 and KCC2, the less selective cation-chloride cotransport inhibitor furosemide $(0.1$ and $1 \mathrm{~mm})$, the specific $\mathrm{KCC} 2$ blockers VU0463271 (0.1 and $1 \mu \mathrm{M})$ and VU0240551 $(10 \mu \mathrm{M})$, the putative KCC2 cotransporter activator CLP257 $(1 \mu \mathrm{M})$, the $\mathrm{GABA}_{\mathrm{A}}$ receptor antagonist SR95531 $(10 \mu \mathrm{M})$, and the sodium voltage gated channel antagonist tetrodotoxin (TTX; $1 \mu \mathrm{M})$. Bumetanide, furosemide, and SR95531 were from Sigma-Aldrich. VU0240551, VU0463271, CLP257, and TTX were from Tocris Bioscience.

\section{Electrophysiological recordings and data analysis}

Extracellular field potentials were recorded in the CA3 and CA1 pyramidal cell layer of organotypic hippocampal slices using custom-made tungsten-coated $50-\mu \mathrm{m}$ wire microelectrodes. The electrical signals were digitized using an analog-to-digital converter DigiData 1322A (Molecular Devices, Inc). AxoScope 10.7 and Clampfit 10.7 (Molecular Devices), Origin 2018 (OriginLab Corporation) and SigmaPlot 11.0 (Systat Software, Inc) programs were used for data acquisition and analyses. Recordings were sampled at $10 \mathrm{kHz}$. Interictal epileptiform discharges (IEDs) were defined as synchronous network-driven bursts characterized by short $(0.1-3 \mathrm{~s})$ duration and large amplitude population spikes. The frequency, duration and amplitude of IEDs substantially varied between recurrent ILDs. ILDs were defined as hyper-synchronous, large-amplitude and high-frequency population spikes followed by sustained ictal-tonic and/or intermittent ictal-clonic after- discharges, with the duration of the population spikes and after-discharge complex lasting $>5 \mathrm{~s}$. Power spectrum analysis was performed on the electrical recordings after filtering with a Bessel high pass filter of $1 \mathrm{~Hz}$ and applying a Hamming window function. The power of the electrical activity was calculated by integrating the root mean square value of the signal amplitude in corresponding time windows and frequency range from 1 to $1000 \mathrm{~Hz}$. For comparison between slices, power was normalized for each slice with the highest value in control conditions.

\section{Two-photon imaging of Clomeleon, quantitative and morphologic analysis}

Neuronal chloride concentration was determined in CA1 pyramidal neurons expressing the ratio-metric chloride indicator Clomeleon (Kuner and Augustine, 2000). High-resolution two-photon excitation laser scanning imaging of the $\mathrm{Cl}^{-}$-sensitive yellow fluorescent protein (YFP) and the $\mathrm{Cl}^{-}$-insensitive cyan fluorescent protein (CFP) was performed on an Olympus Fluoview 1000 MPE microscope. A mode-locked titanium-sapphire laser (MaiTai, Spectra Physics) with 860-nm two-photon excitation was used to generate fluorescence. Emitted light passed through a dichroic mirror and was bandpass filtered through $480 \pm 15 \mathrm{~nm}$ (D480/30) for CFP and a $535 \pm 20-n m$ filter (D535/40) for YFP (FV10-MRCYR/XR). Time series acquisition of 720 frames $(256 \times 256$ pixels for $254.46 \times 254.46 \mu \mathrm{m})$ with 5 - to 10 -s intervals was performed to measure chloride concentration as a function of time in control conditions, during a $30-$ to $60-\mathrm{min}$ period of applications of drugs, and over a 30- to 60-min period of wash-out.

For morphologic analysis, organotypic slices were imaged through the CA1 pyramidal cell layer ( $z$-axis dimension 0 $100 \mu \mathrm{m}, 1$ - to $2-\mu \mathrm{m}$ step size). ImageJ 1.51 software (National Institutes of Health) was used for quantitative analysis. Regions of interest (ROls) were selected using the chloride insensitive CFP fluorescence. The ratio of the YFP/CFP fluorescence intensity was used for $\left[\mathrm{Cl}^{-}\right]_{i}$ calculation (Kuner and Augustine, 2000; Berglund et al., 2008; Glykys et al., 2009). The CFP emission of Clomeleon was used for the high-resolution morphologic analysis (Dzhala et al., 2012).

\section{Statistical analysis}

Group measures are expressed as mean \pm SD or median $(25-75 \%) \pm$ SD as indicated. The Shapiro-Wilk test was used to determine normality of the data. The Student's $t$ test (paired or unpaired) was performed for parametric comparison of normally distributed data. The Wilcoxon signed-rank test (paired data) and Mann-Whitney test (unpaired data, two-tail) were used for non-parametric comparison of arbitrary distributed data. One-way repeated measures (RM) ANOVA was used for multiple comparison of parametric data to evaluate the differences in the mean values among the control and treatment groups. The Friedman RM ANOVA on ranks was used for non-parametric data to determine the differences in the median values among the control and treatment groups. The Tukey's test was used for all pairwise comparisons of the responses to the different treatment groups. The level of significance was set at $p<0.05$.

\section{Results}

\section{Chloride transients during ILDs and baseline chloride changes during epileptogenesis}

Organotypic hippocampal slice cultures from CLM-1 mice expressing the genetically encoded intracellular chloride fluorophore Clomeleon were used as a model of traumatic brain injury and epileptogenesis in vitro (Dyhrfjeld-Johnsen et al., 2010; Dzhala et al., 2012; Dzhala and Staley, 2015). 


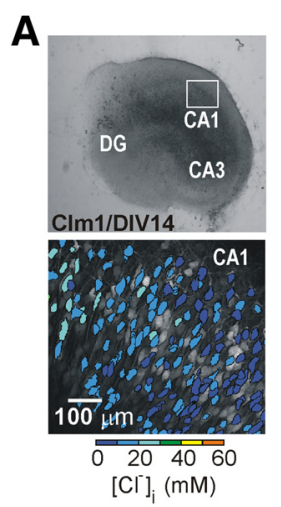

$\mathbf{E}$

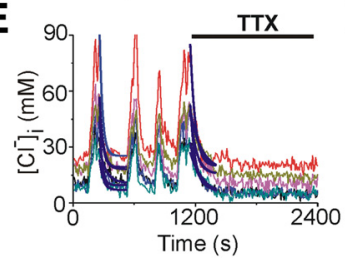

B

C
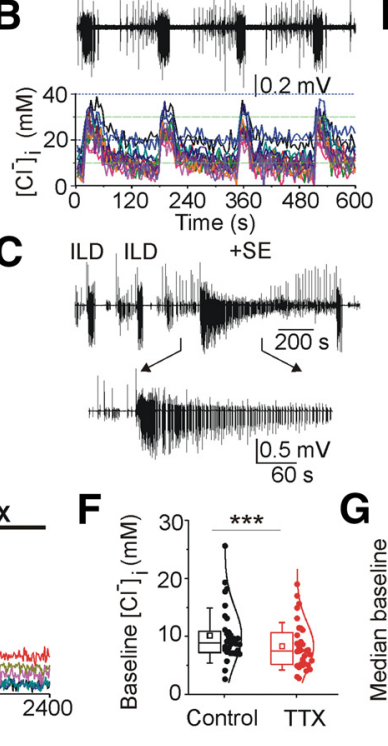

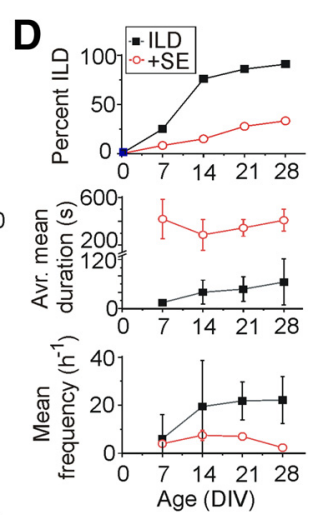

G

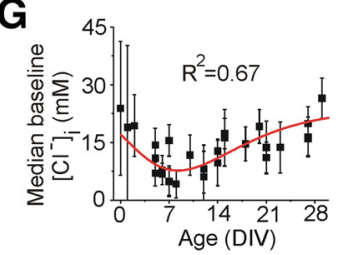

Figure 1. Neuronal chloride accumulation during spontaneous ILDs and epileptogenesis in organotypic hippocampal slices in vitro. $\boldsymbol{A}$, Microphotograph of incubated organotypic hippocampal slice from CLM1 mice captured at DIV14 and corresponding two-photon fluorescence image of the CA1 pyramidal cell layer. Overlays of 50 imaging planes from 0 to $100 \mu \mathrm{m}$ below the slice surface (2$\mu \mathrm{m}$ steps) are shown. Neuronal cell bodies are pseudo colored according to $\left[\mathrm{Cl}^{-}\right]_{\mathrm{i}}$ (Dzhala et al., 2010, 2012). B. Simultaneous extracellular field potential recording and two-photon fluorescence chloride imaging were used to monitor neuronal network activity and $\left[\mathrm{Cl}^{-}\right]_{\mathrm{i}}$ as a function of time. Example of spontaneous recurrent ILDs and corresponding $\left[\mathrm{Cl}^{-}\right]_{\mathrm{i}}$ transients in the CA1 pyramidal cells at DIV14. C, Recurrent ILDs can last from 10 to $20 \mathrm{~s}$ to $>5 \mathrm{~min}$, the ILD duration threshold for SE. Example of recurrent ILDs and SE at DIV14. D, Percentage of slices with spontaneous recurrent ILDs and SE, and corresponding mean duration and frequency of ILDs as a function of age. $\boldsymbol{E},\left[\mathrm{Cl}^{-}\right]_{\mathrm{i}}$ transients in the CA1 pyramidal cells during recurrent ILDs at DIV14. The sodium channel blocker TTX $(1 \mu \mathrm{M})$ rapidly abolished recurrent ILDs and corresponding $\left[\mathrm{Cl}^{-}\right]_{\mathrm{i}}$ transients, and significantly reduced the base line $\left[\mathrm{Cl}^{-}\right]_{\mathrm{i}}$. Exponential fits $(y=A 1 \exp (-x / t 1)+y 0)$ were used to measure base line $\left[\mathrm{Cl}^{-}\right]_{i}(\mathrm{y} 0)$ in individual cells (solid navy curves) during recovery from ILD (adj. $\left.R^{2}=0.9-0.96\right)$. $F$, Box (left) + data (right) plots correspond to median (25-75\%) [Cl-]; in paired cells (filled circles) and their distribution curves; open squares and whisker range indicate mean $\pm \mathrm{SD} ;{ }^{* \star *} p<0.001$ (paired sample Wilcoxon signedranks test). $\mathbf{G}$, Median baseline $\left[\mathrm{Cl}^{-}\right]$in individual slices as a function of age (DIV0-DIV28).

Hippocampal slices were incubated for three to four weeks. Non-invasive extracellular field potential recordings and two-photon fluorescence Clomeleon imaging were performed in the CA1 pyramidal cell layer to monitor neuronal network activity and $\left[\mathrm{Cl}^{-}\right]_{\mathrm{i}}(\mathrm{Fig} .1 A, B)$. The first week latent period was followed by spontaneous ILDs and status epilepticus (SE). Recurrent ILDs were characterized by an initial spike-and-wave bursts followed by secondary ictal tonicclonic discharges, and subsequent postictal depression. SE was defined as continuous ILDs for at least $5 \mathrm{~min}$, or by sustained ictal-like tonic-clonic epileptiform discharges without recovery to baseline activity between the ILDs (Fig. 1C). The incidence of spontaneous ILDs and SE, and the mean duration and frequency of ILDs progressively increased during epileptogenesis (Fig. 1D). The averaged mean duration of ILDs increased from $15 \pm 2.6 \mathrm{~s}$ at DIV6-DIV8 ( $N=12$ slices) to $64.9 \pm 56.2 \mathrm{~s}$ at DIV27-DIV28 ( $N=11$ slices), and the mean frequency of these ILDs increased from $6 \pm 10.2$ ILDs per hour at DIV6-DIV8, $21 \pm 9.7$ ILDs per hour at DIV27DIV28 (Fig. 1D).

Two-photon imaging of Clomeleon was performed during extracellular field potential recordings (Fig. 1B). Under control conditions, baseline $\left[\mathrm{Cl}^{-}\right]_{\mathrm{i}}$ distribution in CA1 pyramidal cells varied from 5 to $20 \mathrm{~mm}$ (Fig. 1A,B). In line with our previous studies (Lillis et al., 2012; Glykys et al.,
2014), $\left[\mathrm{Cl}^{-}\right]_{i}$ transiently increased in all pyramidal cells at the onset of spontaneous ILDs and was further elevated during the ILDs. Pharmacological manipulations of $\mathrm{Cl}$ transport could produce anticonvulsant effects that affect $\left[\mathrm{Cl}^{-}\right]_{\mathrm{i}}$ as a consequence of reduced seizure activity, separately from the consequences of altered transport. To estimate how direct anticonvulsant effects might alter $\left[\mathrm{Cl}^{-}\right]_{\mathrm{i}}$, we applied the sodium channel blocker TTX $(1 \mu \mathrm{M})$. TTX rapidly abolished recurrent ILDs and corresponding $\left[\mathrm{Cl}^{-}\right]_{\mathrm{i}}$ transients (Fig. 1E), and significantly reduced the median baseline $\left[\mathrm{Cl}^{-}\right]_{\mathrm{i}}$ from $8.9(7.15-11) \pm 4.7$ to 7.5 (5.110.8) $\pm 4.1 \mathrm{~mm}[N=6$ slices at DIV11-DIV16, $n=32$ paired cells; Wilcoxon signed-rank test, sum, of negative ranks $(W)=474, Z=3.92, p<0.001$; Fig. $1 F$, suggesting activity dependent baseline neuronal chloride accumulation.

The baseline $\left[\mathrm{Cl}^{-}\right]_{\mathrm{i}}$ in the CA1 pyramidal cell layer progressively decreased during the first week of organotypic slice incubation $[N=29$ slices at DIV0-DIV28, nonlinear extreme curve fit: $\mathrm{YO}=23.7 \pm 2.36$ (median $\pm \mathrm{SE}$ ), $\mathrm{XC}=$ $8.3 \pm 1.1, \mathrm{~A}=-16 \pm 2.3 \mathrm{M} ; R^{2}=0.67$; ANOVA: $F=115.3$, $p<0.001$; Fig. 1G]. This progressive decrease in baseline $\left[\mathrm{Cl}^{-}\right]_{\mathrm{i}}$ and corresponding negative shift in $\mathrm{E}_{\mathrm{Cl}}$ during the first week of incubation correlated with a decrease in the number of acutely damaged cells with higher $\left[\mathrm{Cl}^{-}\right]_{\mathrm{i}}$ because of dissection (Berdichevsky et al., 2012; Dzhala et 
A
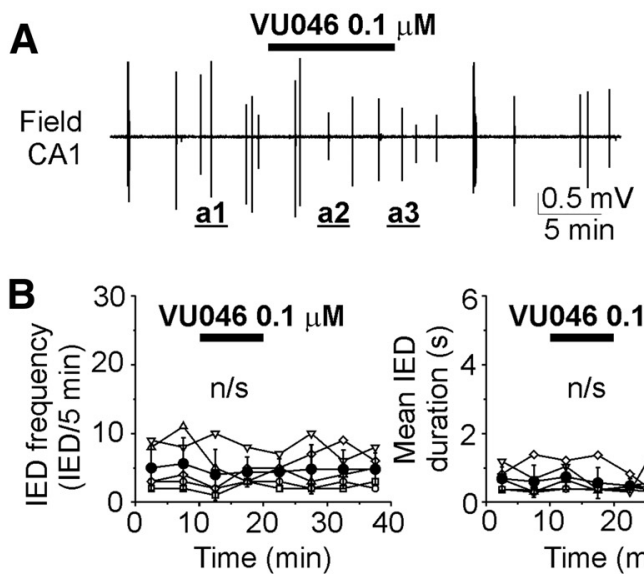

C
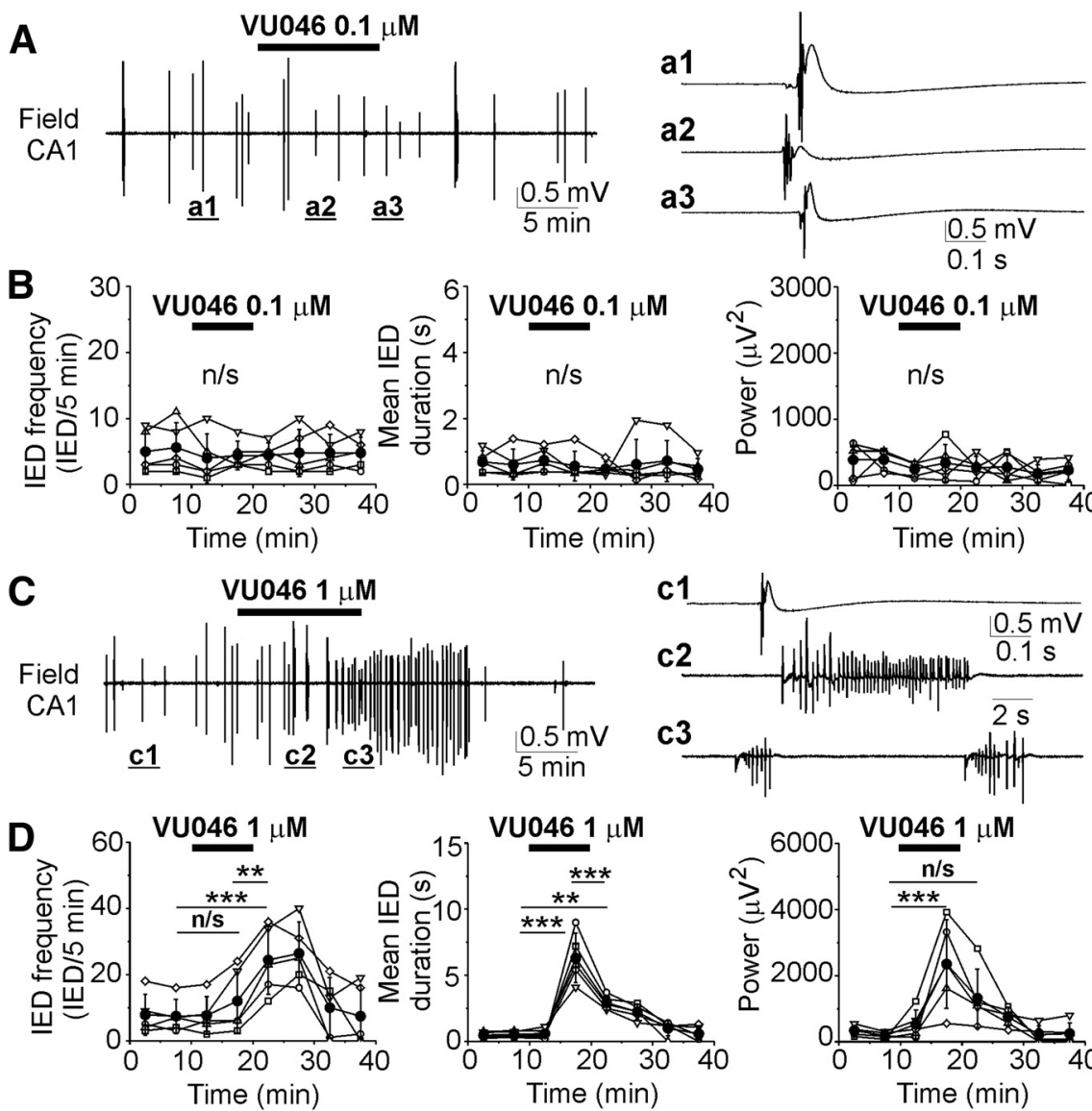

$0.1 \mathrm{~s}$
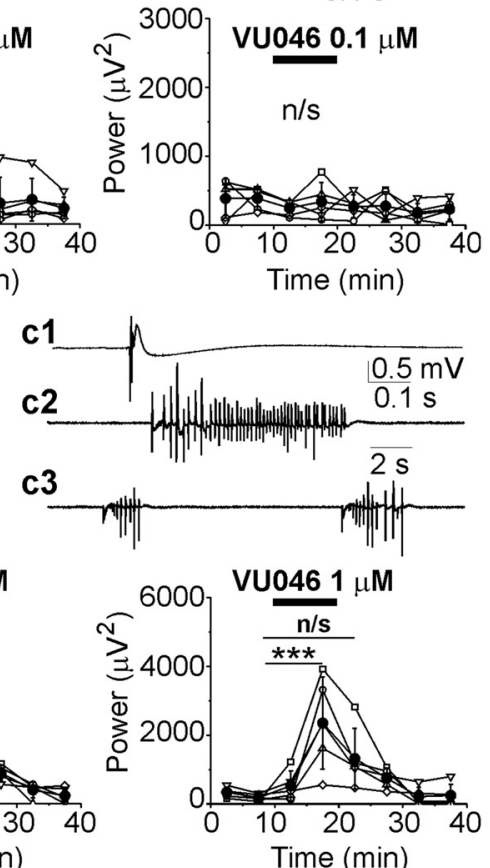

Figure 2. Effects of the KCC2 blocker VU0463271 on recurrent IEDs at DIV5-DIV7. A, C, Extracellular field potential recordings in the CA1 pyramidal cell layer in the organotypic hippocampal slices at DIV6 before (control), during and after application of $0.1 \mu \mathrm{M}$ (A) and $1 \mu \mathrm{M}(\boldsymbol{C})$ VU0463271 for $10 \mathrm{~min}$. Expansion of IEDs in control and in the presence of VU0463271. B, D, Corresponding summary plots of the frequency and mean duration of recurrent IEDs in individual cultures (open symbols) and corresponding power of electrical activity in 5-min windows. Filled symbols indicate group mean \pm SD. VU0463271 $(1 \mu \mathrm{M})$ significantly increased the mean frequency, duration, and power of epileptiform discharges ( $\mathrm{n} / \mathrm{s}$ corresponds to $p>0.05 ;{ }^{*} p<0.05 ;{ }^{* *} p<0.01 ;{ }^{* * *} p<0.001$, one-way RM ANOVA, Tukey's test).

al., 2012) as well as with postnatal changes in CCC expression (Stein et al., 2004; Dzhala et al., 2005; Takayama and Inoue, 2010). Starting from the second week of incubation, the median baseline $\left[\mathrm{Cl}^{-}\right]_{\mathrm{i}}$ progressively increased with corresponding positive shifts in $\mathrm{E}_{\mathrm{Cl}}$ and the increasing incidence, duration and frequency of spontaneous ILDs (Fig. $1 D, G)$. Positive shifts in $\mathrm{E}_{\mathrm{Cl}}$ and corresponding changes in GABA action are thought to contribute to facilitation of recurrent epileptiform discharges and resistance of ILDs to GABAergic anticonvulsants (Dzhala and Staley, 2003; Dzhala et al., 2010; Khazipov et al., 2015; Glykys et al., 2017). We therefore determined the contribution of KCC2 cotransporter activity to neuronal chloride elevation and extrusion rates, and facilitation of recurrent ILDs during epileptogenesis.

\section{The selective KCC2 inhibitor VU0463271 reduced chloride extrusion and increased duration of ILDs}

VU0463271, a potent and selective inhibitor of the neuronal $\mathrm{K}^{+}-\mathrm{Cl}^{-}$cotransporter, $\mathrm{KCC} 2\left(\mathrm{IC}_{50}=61 \mathrm{~nm}\right)$, exhibits $>100$-fold selectivity versus the NKCC1 (Delpire et al.,
2012). Selective inhibition of KCC2 with VU0463271 led to hyperexcitability and epileptiform discharges in hippocampal slices exposed to low $\mathrm{Mg}^{2+}$ and also in vivo (Sivakumaran et al., 2015). We determined the contribution of $\mathrm{KCC} 2$ cotransporter activity to baseline $\left[\mathrm{Cl}^{-}\right]_{i}$ elevation and extrusion rates during recurrent ILDs, and their correlation with the frequency, duration, and power of ILDs.

Extracellular field potential recordings were performed in the CA1 pyramidal cell layer in the organotypic hippocampal slices at DIV5-DIV7 (Fig. 2) and DIV14-DIV21 (Fig. 3 ) before (control), during and after application of VU0463271 (0.1 and $1 \mu \mathrm{M})$. At DIV5-DIV7, spontaneous neuronal activity was characterized by multiunit activity and population bursts reminiscent of interictal-like epileptiform discharges (IEDs) (Dyhrfjeld-Johnsen et al., 2010; Berdichevsky et al., 2012). Bath application of VU0463271 at low concentration $(0.1 \mu \mathrm{m}$ for $10 \mathrm{~min})$ did not change the frequency $(N=5$ slices, one-way RM ANOVA: $D F=39$, $F=0.328, p=0.934$ ) and duration of IEDs (one-way RM ANOVA: $D F=39, F=0.345, p=0.926)$, nor the power of electrical activity in all pairwise 5-min windows (one-way 

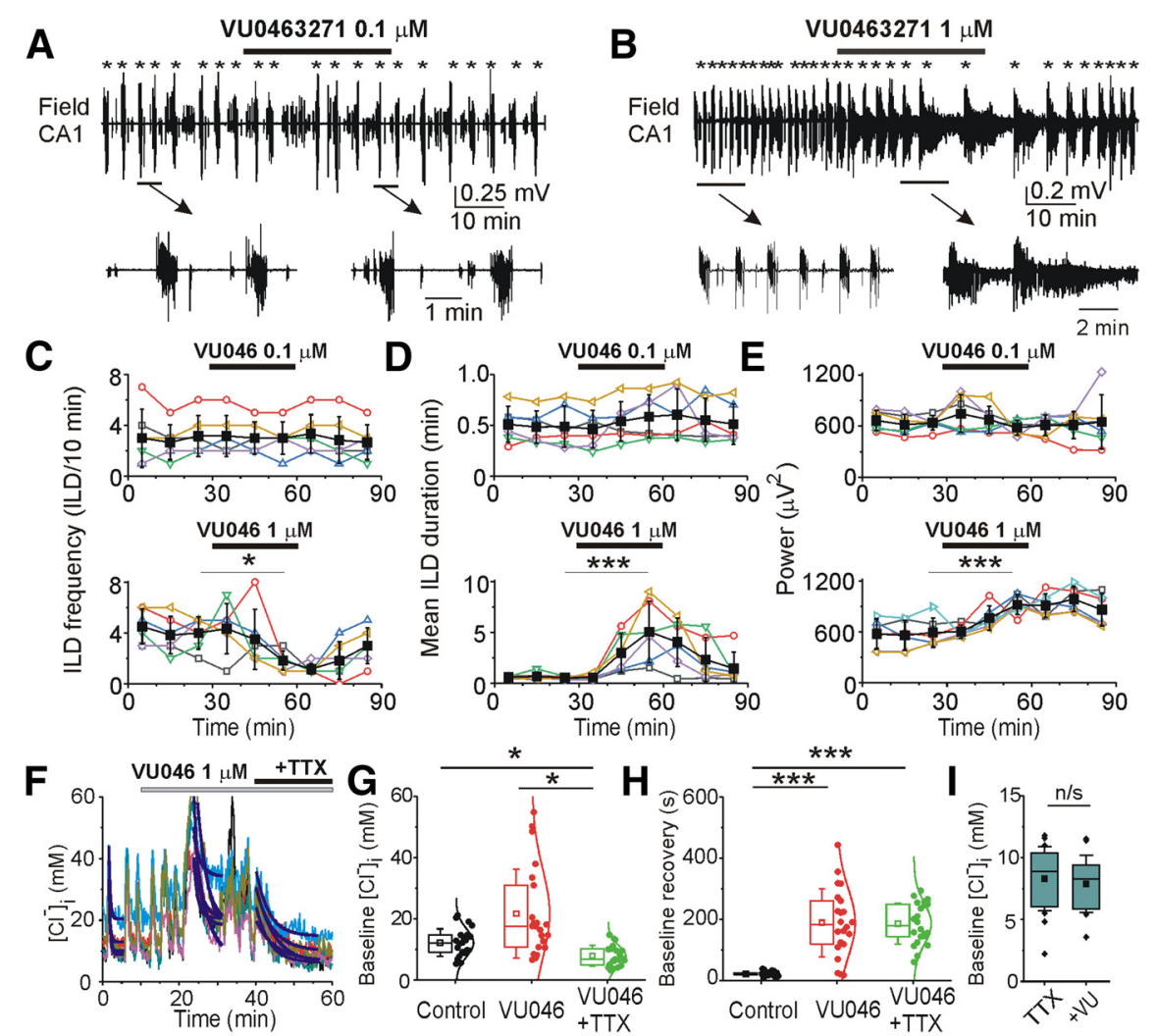

Figure 3. Effects of the KCC2 blocker VU0463271 on recurrent ILDs and intracellular chloride at DIV14-DIV21. A, B, Extracellular field potential recordings in the CA1 pyramidal cell layer in the organotypic hippocampal slices at DIV18 before (control), during and after application of $0.1 \mu \mathrm{M}(\boldsymbol{A})$ and $1 \mu \mathrm{M}(\boldsymbol{B})$ VU0463271 for $30 \mathrm{~min}$. Expansion of ILDs in control and in the presence of VU0463271. $\boldsymbol{C}-\boldsymbol{E}$, Corresponding summary plots of the frequency and mean duration of recurrent ILDs and corresponding power of electrical activity in 10-min windows in individual slice cultures (open symbols). Filled symbols indicate group mean \pm SD. VU0463271 (1 $\mu \mathrm{m}$ ) significantly reduced the mean frequency of ILDs and increased their duration and power ( ${ }^{*} \operatorname{corresponds}$ to $p<0.05$; ${ }^{* * *} p<0.01$, one-way RM ANOVA, Tukey's test). $\boldsymbol{F}$, Exponential fit ( $\mathrm{y}=\mathrm{A} 1 \exp (-(\mathrm{x}-\mathrm{x} 0) / \mathrm{t} 1)+\mathrm{y} 0)$ was used to measure base line $\left[\mathrm{Cl}^{-}\right]_{\mathrm{i}}(\mathrm{y} 0)$ and decay time (t1) of base line $\left[\mathrm{Cl}^{-}\right]_{\mathrm{i}}$ recovery in individual cells (solid navy curves) during ILD in control, during application of VU0463271 and TTX (adj. $\left.R^{2}=0.9-0.96\right) . F-H$, VU0463271 $(1 \mu \mathrm{M})$ increased base line $\left[\mathrm{Cl}^{-}\right]_{\mathrm{i}}(\mathrm{y} 0)$ and delayed decay time of baseline chloride recovery (t1) during ILDs. G, TTX $(1 \mu \mathrm{M})$ abolished ILDs and slowly reduced the median baseline $\left[\mathrm{Cl}^{-}\right]_{\mathrm{i}}\left({ }^{*} p<0.05, \mathrm{Friedman}^{-}\right.$ RM ANOVA on ranks, Tukey's test). $\boldsymbol{H}$, Decay time of baseline $\left[\mathrm{Cl}^{-}\right]_{\mathrm{i}}$ recovery during application of $\Pi \mathrm{TX}$ in the presence of VU0463271 was significantly higher as in control ${ }^{\star \star *} p<0.001$, one-way RM ANOVA, Tukey's test). $\boldsymbol{I}$, Effects of VU0463271 in the presence of TTX on $\left[\mathrm{Cl}^{-}\right]_{\mathrm{i}}$. VU0463271 application in the presence of TTX did not significantly change the median baseline chloride concentration ( $p>0.05$, Wilcoxon signed-ranks test).

RM ANOVA: $\mathrm{DF}=39, \quad F=0.753, p=0.63$; Fig. $2 A, B)$. VU0463271 at the higher concentration ( $1 \mu \mathrm{m}$ for $10 \mathrm{~min})$ significantly increased the frequency, duration and power of spontaneous IEDs (Fig. 2C,D). VU0463271 (1 $\mu \mathrm{M})$ progressively increased the mean frequency of IEDs from $7.4 \pm 5.12 \mathrm{IED} / 5 \mathrm{~min}$ in control to $12 \pm 9.7 \mathrm{IEL} / 5 \mathrm{~min}$ in the presence of VU0463271 and then to $24.4 \pm 10.45 \mathrm{IED} / 5 \mathrm{~min}$ during wash $[N=5$; one-way RM ANOVA: $D F=39, F=15.2$, $p<0.001$; Tukey's test: VU04663271 (15-20 min) vs control $(5-10 \mathrm{~min}), \mathrm{df}=4.6, q=2.267, p=0.745$; wash $(20$ $25 \mathrm{~min}$ ) vs control (5-10 $\mathrm{min}), \mathrm{df}=17, q=8.377, p<0.001$; wash $(20-25 \mathrm{~min})$ vs VU04663271 $(15-20 \mathrm{~min}), \mathrm{df}=12.4$, $q=6.11, p=0.004$; Fig. 2D]. VU0463271 (1 $\mu \mathrm{M})$ significantly increased the corresponding group mean duration of IEDs from $0.5 \pm 0.23 \mathrm{~s}$ in control to $6.3 \pm 1.87 \mathrm{~s}$ in the presence of VU0463271 and then reduced to $2.9 \pm 0.54 \mathrm{~s}$ during wash $[N=5$; one-way RM ANOVA: $\mathrm{DF}=39, F=32.4$, $p<0.001$; Tukey's test: VU04663271 (15-20 min) vs control
$(5-10 \mathrm{~min}), \mathrm{df}=7.79, q=16.26, p<0.001$; wash $(20-$ $25 \mathrm{~min})$ vs control $(5-10 \mathrm{~min}), \quad \mathrm{df}=2.41, \quad q=6.77$, $p=0.001$; wash (20-25 min) vs VU04663271 (15-20 min), $\mathrm{df}=-3.38, q=9.49, p<0.001$; Fig. $2 D$ ]. The corresponding power of electrical activity in 5-min windows significantly increased from $183.2 \pm 98.9 \mu \mathrm{V}^{2}$ in control to $2352.2 \pm 1339.9 \mu \mathrm{V}^{2}$ in the presence of VU0463271 $(15-20 \mathrm{~min})$ and then reduced to $1323.2 \pm 882.5 \mu \mathrm{V}^{2}$ $[N=5$; one-way RM ANOVA: $\mathrm{DF}=39, \quad F=8.807$, $p<0.001$; Tukey's test: VU04663271 (15-20 min) vs control (5-10 min), $\mathrm{df}=2169, q=8.54, p<0.001$; wash $(20-25 \mathrm{~min})$ vs control $(5-10 \mathrm{~min}), \mathrm{df}=1139, q=4.49$, $p=0.062$; wash (20-25 min) vs VU04663271 (15-20 min), $\mathrm{df}=-1028, q=4.05, p=0.12$; Fig. $2 D$ ].

At DIV14-DIV21, spontaneous neuronal network activity was characterized by short inter-ILDs and prolonged ILDs, reminiscent of seizure-like activity in vivo (Fig. $3 A, B$ ). VU0463271 at the lower concentration $(0.1 \mu \mathrm{M})$ did not 


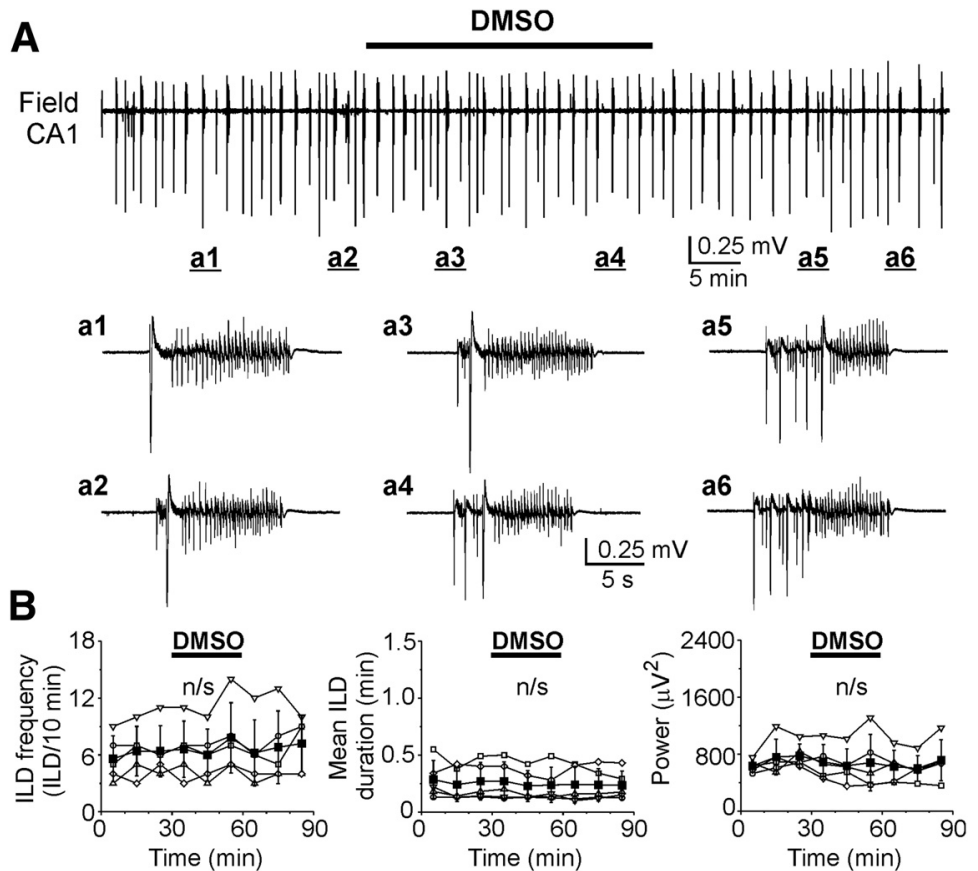

Figure 4. Effects of DMSO on recurrent ILDs at DIV12-DIhttV17. A, Extracellular field potential recording in the CA1 pyramidal cell layer in the organotypic hippocampal slices at DIV14 before (control), during and after application of DMSO (100 $\mu \mathrm{l} / 100 \mathrm{ml})$. Expansion of ILDs in control $(\mathbf{a} 1, \mathbf{a} 2)$, in the presence of DMSO $(\mathbf{a} 3, \mathbf{a} 4)$, and during washout of DMSO (a5, a6). B, Corresponding summary plots of the frequency and mean duration of recurrent ILDs and corresponding power of electrical activity in 10-min windows in individual slice cultures (open symbols). Filled symbols indicate group mean $\pm \mathrm{SD}$ ( $\mathrm{n} / \mathrm{s}$ corresponds to $p>0.05$, one-way RM ANOVA).

significantly change the frequency $(N=6$ slices, one-way RM ANOVA: $D F=53, F=0.699, p=0.69$; Fig. $3 A, C)$ and duration (one-way RM ANOVA: $\mathrm{DF}=53, \quad F=1.198$, $p=0.325$; Fig. $3 D$ ) of recurrent ILDs, nor the power of electrical activity in 10-min windows (one-way RM ANOVA: $\mathrm{DF}=53, F=0.799, p=0.607$; Fig. $3 E$ ). VU0463271 at the higher concentration $(1 \mu \mathrm{M})$ significantly reduced the mean frequency of recurrent ILDs from $4 \pm 1.26 \mathrm{ILD} / 10 \mathrm{~min}$ in control to $1.83 \pm 0.75 \mathrm{ILD} / 10 \mathrm{~min}$ during VU04663271 (1 $\mu \mathrm{M})$ application $[N=6$ slices; one-way RM ANOVA: $\mathrm{DF}=53, F=4.44, p<0.001$; Tukey's test: VU04663271 (50-60 min) vs control $(20-30 \mathrm{~min})$, df $=-2.17, q=4.88$, $p=0.032$; Fig. $3 B, C]$ and substantially increased the group mean duration of recurrent ILDs from $0.56 \pm 0.3$ to $5.5 \pm 3 \mathrm{~min}(N=6$; one-way RM ANOVA: $\mathrm{DF}=53, F=8.91$, $p<0.001$; Tukey's test: VU04663271 vs control, $\mathrm{df}=4.9$, $q=7.98, p<0.001$; Fig. $3 D$ ), resulting in SE. The corresponding power of electrical activity in 10-min windows significantly increased from $591.6 \pm 171.7$ to $920.2 \pm$ $117.4 \mu \mathrm{V}^{2}(N=6$, one-way RM ANOVA: DF $=53, F=$ 12.66, $p<0.001$; Tukey's test: VU04663271 vs control, $\mathrm{df}=328.6, q=6.83, p<0.001 ;$ Fig. $3 E$ ).

Under similar experimental conditions (DIV12-DIV17), bath application of dimethylsulfoxide (DMSO; $100 \mu \mathrm{l} / 100$ $\mathrm{ml}$ ), an organic solvent for VU04663271, did not change the frequency of ILDs ( $N=5$ slices, one-way RM ANOVA: $\mathrm{DF}=44, F=2.04, p=0.073$; Fig. $4 A, B)$, duration of ILDs $(N=5$, one-way RM ANOVA: $\mathrm{DF}=44, F=0.798, p=0.61$; Fig. $4 B$ ), and power of electrical activity in all pairwise 10min windows $(N=5$, one-way RM ANOVA: $D F=44$,
$F=1.141, p=0.364 ;$ Fig. $4 B$ ). The increased duration and power of ILDs in the presence of VU04663271 (1 $\mu \mathrm{M})$ suggest that KCC2 transport activity contributes to recovery of baseline $\left[\mathrm{Cl}^{-}\right]_{i}$ and GABAergic inhibition during epileptiform discharges, and may contribute to termination of ILDs, although the concentration of antagonist required was substantially higher than the reported $\mathrm{IC}_{50}$ for $\mathrm{KCC} 2$ (Delpire et al., 2012).

To test whether these "dual" effects of VU04663271 ( $1 \mu \mathrm{M}$; a reduction of the frequency of recurrent ILDs, but an increase in the duration and power of ILDs) were associated with changes in neuronal baseline $\left[\mathrm{Cl}^{-}\right]_{i}$ and chloride transport, we compared the baseline $\left[\mathrm{Cl}^{-}\right]_{\mathrm{i}}$ and decay time constant of $\left[\mathrm{Cl}^{-}\right]_{\mathrm{i}}$ extrusion during recurrent ILDs in control conditions, during application of VU04663271, and during consecutive application of the sodium channel blocker TTX in the presence of VU04663271 (Fig. 3F-H). TTX application blocks seizure activity directly, providing a means to assess the effects of the intensity of ILD activity on $\left[\mathrm{Cl}^{-}\right]_{\mathrm{i}}$ levels and kinetics separately from effects on $\mathrm{Cl}$ transport. Bath application of VU04663271 (1 $\mu \mathrm{M}$ for $30 \mathrm{~min}$ ) increased the median baseline chloride concentration from $12.1(9.2-14.7) \pm 4.5$ to $17.7(10.8-31) \pm 14.4$ $\mathrm{mM}$, and $\left[\mathrm{Cl}^{-}\right]_{\mathrm{i}}$ remained elevated during intermittent ILDs. Subsequent application of TTX $(1 \mu \mathrm{M})$, in the continued presence of VU0463271, abolished ILDs and significantly reduced the median baseline $\left[\mathrm{Cl}^{-}\right]_{\mathrm{i}}$ to $6.9(5-10.3) \pm 3.3$ $\mathrm{mm}[N=4$ slices at DIV14-DIV21, $n=24$ paired cells; Friedman RM ANOVA on ranks: $\chi^{2}=36.3, p<0.001$; Tukey's test: control compared with VU0463271, 


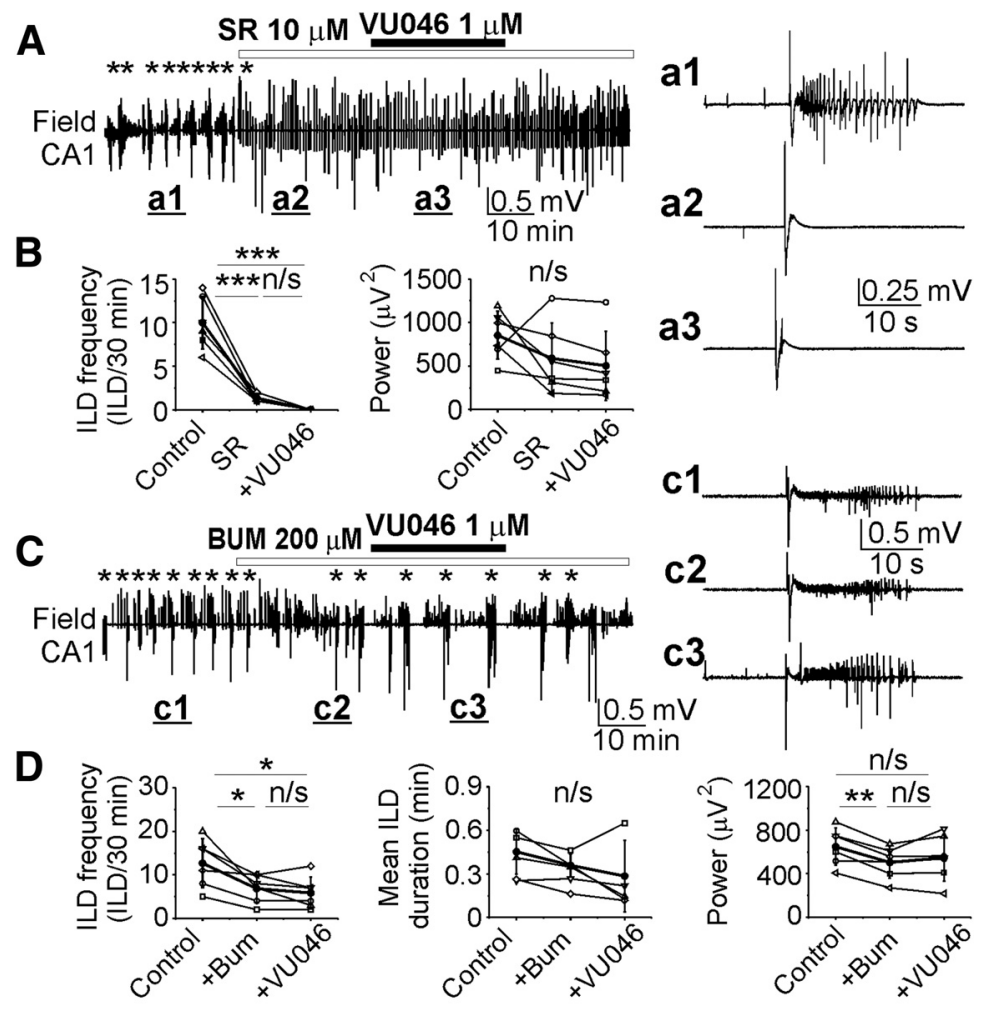

Figure 5. Selectivity of KCC2 blocker VU0463271. A, C, Extracellular field potential recordings in the CA1 pyramidal cell layer in the organotypic hippocampal slices in vitro. $\boldsymbol{A}, \boldsymbol{B}$, Application of the GABA $\mathrm{A}_{\mathrm{A}}-\mathrm{R}$ antagonist SR95531 (10 $\left.\mu \mathrm{M}\right)$ abolished spontaneous ILDs and induced large amplitude IEDs. Subsequent application of VU0463271 (1 $\mu \mathrm{M})$ in the presence of SR95531 did not change the mean frequency of ILDs discharges ( $\mathrm{n} / \mathrm{s}, p>0.05 ;{ }^{\star * *} p<0.001$; one-way RM ANOVA, Tukey's test) and power of electrical activity ( $p>0.05$; one-way RM ANOVA). A, a1-a3, Expansion of ILD in control (a1) and IEDs in the presence of SR95531 (a2) and VU0463271 (a3). C, D, Application of VU0463271 (1 $\mu \mathrm{M})$ in the presence of NKCC1 and KCC2 blocker bumetanide (200 $\mu \mathrm{M})$ did not change the mean frequency and duration of ILDs, and the mean power of electrical activity ( $p>0.05$, one-way RM ANOVA, Tukey's test). c1-c3, Expansion of ILDs in control (c1), during application of bumetanide (c2), and in the presence of VU0463271 (c3).

difference of ranks $(\mathrm{df})=12, q=2.6, p>0.05$; control vs TTX in the presence of VU0463271, $d f=27, q=5.8$, $p<0.05$; VU0463271 vs TTX in the presence of VU0463271, df =39, $q=8.3, p<0.05$; Fig. 3G]. The corresponding decay time constant of baseline $\left[\mathrm{Cl}^{-}\right]_{i}$ extrusion (recovery) during ILDs significantly increased from the mean $21.4 \pm 7.6 \mathrm{~s}$ in control to $188.1 \pm 111 \mathrm{~s}$ in the presence of VU04663271, and subsequent application of TTX in the presence of VU0463271 abolished $\left[\mathrm{Cl}^{-}\right]_{i}$ transients and recovered baseline $\left[\mathrm{Cl}^{-}\right]_{\mathrm{i}}$ with a time constant of $185.5 \pm 67.2 \mathrm{~s}[N=4$ slices at DIV14-DIV21, $n=24$ paired cells; one-way RM ANOVA: difference of variations (DF) $=65, F=38.6, p<0.001$; Tukey's test: control compared with VU04663271, difference of means (df) = $-166.7, q=10.84, p<0.001$; control vs TTX in the presence of VU04663271, df $=-164.1, q=10.68, p<0.001$; VU04663271 vs TTX in the presence of VU04663271, $\mathrm{df}=-2.6, q=0.166, p=0.993$; Fig. $3 H]$. In contrast, VU0463271 application in the presence of TTX (Fig. 3/) did not significantly change the median baseline chloride concentration from $8.5(5.7-11.8) \pm 2.7$ to 8.3 (5.79.9) $\pm 2.4 \mathrm{~mm}(N=4$ slices at DIV14-DIV17, $n=24$ paired cells; Wilcoxon signed-rank test: $W=200, Z=1.41$, $p=0.16$; Fig. 3/). Thus, the increased duration and power of intermittent ILDs in the presence of the KCC2 blocker VU04663271 correlates with increased magnitude and duration of $\left[\mathrm{Cl}^{-}\right]_{i}$ elevation, consistent with a reduced extrusion rate of $\left[\mathrm{Cl}^{-}\right]_{\mathrm{i}}$.

We next used pharmacological tools to determine whether $\mathrm{GABA}_{\mathrm{A}}-\mathrm{R}$ block prevents the epileptogenic action of the KCC2 antagonist VU04663271 (Fig. 5A,B). Under similar experimental conditions (DIV14-DIV18), bath application of the $\mathrm{GABA}_{A}-\mathrm{R}$ antagonist SR95531 (10 $\mu \mathrm{M})$ reduced the mean frequency of spontaneous ILDs from $10 \pm 3$ to $1.33 \pm 0.52 \mathrm{ILD} / 30 \mathrm{~min}$ and induced large amplitude inter-ILDs (IEDs). Subsequent application of VU04663271 $(1 \mu \mathrm{M})$, in the continued presence of SR95531, did not change the mean frequency of epileptiform discharges ( $N=6$ slices at DIV14-DIV18; one-way RM ANOVA: $D F=17, F=59.85, p<0.001$; Tukey's test: control compared with SR95531, $\mathrm{df}=8.7, q=12.3$, $p<0.001$; control compared with VU04663271 in the presence of SR95531, $\mathrm{df}=10.0, q=14.3, p<0.001$; SR95531 compared with VU04663271 in the presence of SR95531, $\mathrm{df}=1.33, q=1.9, p=0.405$; Fig. $5 B$ ). The net effect of the changes in ictal and interictal activity was a non-significant decrease in the mean power of electrical activity by $31 \%$, from $852.5 \pm 275.3 \mu \mathrm{V}^{2}$ in control to $588.1 \pm 408.32 \mu \mathrm{V}^{2}$ in the presence of SR95531, and to $503.3 \pm 396.6 \mu \mathrm{V}^{2}$ during subsequent 
application of VU04663271 $(1 \mu \mathrm{M})$, in the continued presence of SR95531 ( $N=6$; one-way RM ANOVA: $\mathrm{DF}=17, F=2.231, p=0.16$; Fig. $5 B$ ). These data suggest that the epileptogenic effects of the KCC2 blocker VU04663271 on the duration and power of ILDs require activation of $\mathrm{GABA}_{\mathrm{A}}$ receptors.

We also tested whether cation-chloride cotransport was necessary for the epileptogenic effects of VU04663271 (Fig. $5 C, D$ ). Under similar experimental conditions (DIV14DIV19), bath application of a concentration of bumetanide $(200 \mu \mathrm{M})$ that blocks both NKCC1 and KCC2 cotransporters significantly reduced the mean frequency of spontaneous ILDs from $12.67 \pm 5.6$ to $6.8 \pm 3.2 \mathrm{ILD} / 30 \mathrm{~min}$. Subsequent application of $1 \mathrm{uM}$ VU04663271, in the continued presence of bumetanide, did not significantly change the mean frequency of ILDs to $5.8 \pm 3.7$ ILD/ 30 min ( $N=6$ slices at DIV14-DIV19; one-way RM ANOVA: $D F=17, F=7.9, p=0.009$; Tukey's test: control compared with bumetanide, $\mathrm{df}=5.87, q=4.4, p=0.026$; control vs VU04663271 in the presence of bumetanide, $\mathrm{df}=6.87, q=5.2, p=0.011$; bumetanide vs VU04663271 in the presence of bumetanide, $\mathrm{df}=1, q=76, p=0.855$; Fig. 5D). In addition, both bumetanide and subsequent VU04663271 applications did not change the mean duration of ILDs ( $N=5$ slices; one-way RM ANOVA: $D F=14$, $F=2.4, p=0.152$; Fig. $5 D$ ). The net effect of the changes in ictal and interictal activity was a significant decrease in the mean power of electrical activity by $23 \%$ from $648.8 \pm 172.4 \mu \mathrm{V}^{2}$ in control to $504.17 \pm 147.3 \mu \mathrm{V}^{2}$ in the presence of bumetanide (Fig. 5D). Subsequent application of $1 \mu \mathrm{m}$ VU04663271, in the continued presence of bumetanide, did not significantly change the mean power of electrical activity to $547.6 \pm 218.1 \mu \mathrm{V}^{2}(N=6$; one-way RM ANOVA: DF $=17, F=7.6, p=0.01$; Tukey's test: control compared with bumetanide, $\mathrm{df}=144.7, q=5.36$, $p=0.009$; control vs VU04663271 in the presence of bumetanide, $\mathrm{df}=101.17, q=3.75, p=0.06$; bumetanide vs VU04663271 in the presence of bumetanide, $\mathrm{df}=-43.5$, $q=1.62, p=0.51$; Fig. $5 D$ ). These results suggest that KCC2 transporter activity is functional during recurrent ILDs, that VU04663271 antagonizes KCC2, and that this antagonism is necessary for the observed increase in the duration and power of ILDs, and induction of electrical SE (Fig. 3).

\section{Furosemide suppressed recurrent ILDs and delayed chloride extrusion}

The loop diuretic furosemide acts to inhibit both NKCC and $\mathrm{KCC}$ with about equal potency $\left(\mathrm{K}_{\mathrm{i}}=25-50 \mu \mathrm{M}\right)$. In contrast to the epileptogenic action of the KCC2 inhibitor VU0463271 (Figs. 2, 3), high concentrations of furosemide (1-2 mM) demonstrate strong anti-ictal effects in various in vitro models of epilepsy (Hochman et al., 1995; Gutschmidt et al., 1999; Haglund and Hochman, 2005; Blauwblomme et al., 2018). To address these discrepancies, we determined the effects of furosemide $(0.1 \mathrm{~mm}$ and $1 \mathrm{~mm})$ on spontaneous epileptiform discharges alone and in combination with $\mathrm{GABA}_{\mathrm{A}}$ receptor inhibitor SR95531, NKCC1 blocker Bumetanide and the low-affinity KCC2 blocker VU0240551 (Figs. 6, 7).
Control extracellular field potential recordings in the CA1 pyramidal cell layer revealed spontaneous IEDs and ILDs in all hippocampal slice cultures at DIV16-DIV19. Furosemide at low concentration $(0.1 \mathrm{~mm})$ significantly decreased the mean frequency of ILDs from $3 \pm 0.89$ to $1.5 \pm 0.55 \mathrm{ILD} / 10 \mathrm{~min}(N=6$ slices; paired sample $t$ test, $t=4.39, \mathrm{df}=5, p=0.007$; Fig. $6 A, C)$ and increased the mean frequency of IEDs from $10 \pm 7.1$ to $22.8 \pm 18.6$ IED/ $10 \mathrm{~min}$ (paired sample $t$ test, $t=-1.94$, df $=4, p=0.12$; Fig. $6 D$ ). The net effect of the changes in ictal and interictal activity was a decrease in the mean power of electrical activity by $35 \%$, from $656.8 \pm 222.9$ to $427.7 \pm 93.6 \mu \mathrm{V}^{2}$ (paired sample $t$ test, $t=1.92, \mathrm{df}=5, p=0.11$; Fig. $6 E$ ). Furosemide at high concentration (1 $\mathrm{mm}$ ) abolished ILDs during $30 \mathrm{~min}$ of application ( $N=5$ slices; paired sample $t$ test, $t=6.51$, $\mathrm{df}=4, p=0.003$; Fig. $6 C$ ) but significantly increased the mean frequency of IEDs from $9.2 \pm 10.7$ to $40 \pm 19 \mathrm{IED} / 10 \mathrm{~min}$ ( $N=5$ slices; paired sample $t$ test, $t=$ -3.45 , df $=4, p=0.023$; Fig. $6 D$ ). These changes resulted in a net decrease in the mean power of electrical activity by $65 \%$, from $682.1 \pm 153.1$ to $236.7 \pm 152.6 \mu \mathrm{V}^{2}(N=5$; paired sample $t$ test, $t=5.7, \mathrm{df}=4, p=0.004$; Fig. $6 D$ ).

We next determined whether the anticonvulsant effects of furosemide correlate with changes in baseline $\left[\mathrm{Cl}^{-}\right]_{i}$ and the rate of $\left[\mathrm{Cl}^{-}\right]_{i}$ extrusion during suppression of recurrent ILDs (Fig. $6 F-L$ ). Bath application of low concentrations of furosemide $(0.1 \mathrm{~mm})$ did not significantly change the median baseline $\left[\mathrm{Cl}^{-}\right]_{\mathrm{i}}$ between ILDs from $9.6(5.8-13.4) \pm 5.3$ to $8.3(6.54-13.75) \pm 5.24 \mathrm{~mm}(N=4$ slices, $n=27$ paired cells; paired sample Wilcoxon signed-rank test: $W=167$, $Z=0.47, p=0.64$; Fig. $6 F, H)$. High concentrations of furosemide (1 $\mathrm{mm}$ ) abolished recurrent ILDs and corresponding $\left[\mathrm{Cl}^{-}\right]_{\mathrm{i}}$ transients and significantly reduced the median baseline $\left[\mathrm{Cl}^{-}\right]_{\mathrm{i}}$ from $12.8(7.7-17.3) \pm 5.9$ to 9.9 (5.2-13.6) $\pm 5.6 \mathrm{~mm}(N=4$ slices at DIV13-DIV17, $n=27$ paired cells; paired sample Wilcoxon signed-rank test: $W=347$, $Z=4.34, p<0.001$; Fig. $6 G, H)$. We also compared the effects of furosemide (1 mM) on baseline $\left[\mathrm{Cl}^{-}\right]_{\mathrm{i}}$ and the postictal decay time constant of $\left[\mathrm{Cl}^{-}\right]_{i}$ extrusion with the corresponding effects of TTX, and furosemide in the presence of TTX (Fig. 6/-L). The sodium channel blocker TTX $(1 \mu \mathrm{M})$ rapidly abolished recurrent ILDs and significantly reduced the median baseline $\left[\mathrm{Cl}^{-}\right]_{\mathrm{i}}$ from 9.1 (7.67-11.6) \pm 3.1 to $6.6(5.3-9.9) \pm 2.5 \mathrm{~mm}$, and subsequent application of furosemide $(1 \mathrm{~mm})$ in the presence of TTX did not change the median baseline $\left[\mathrm{Cl}^{-}\right]_{\mathrm{i}}$ to $6.7(5.8-9.1) \pm 2.3$ $\mathrm{mm}(N=4$ slices at DIV13-DIV17, $n=17$ paired cells; Friedman RM ANOVA on ranks: $\chi^{2}=13.2, p=0.001$; Tukey's test: control compared with TTX, $\mathrm{df}=16, q=3.96$, $p<0.05$; control compared with furosemide in the presence of TTX, df $=20, q=4.85, p<0.05$; TTX compared with furosemide in the presence of $\Pi \mathrm{TX}, \mathrm{df}=4, q=0.97$, $p>0.05$; Fig. $6 J$ ). The median decay time constant of chloride extrusion during $\Pi \mathrm{TX}$ application and suppression of ILDs was $65(48.9-112.7) \pm 66.9 \mathrm{~s}(N=5$ slices at DIV14-DIV17, $n=30$ cells; Fig. $6 L$ ), significantly lower compared with corresponding value 242.7 (187-328.1) \pm $167.9 \mathrm{~s}(N=5$ slices at DIV14-DIV17, $n=31$ cells; Fig. $6 L$ ) during furosemide application (Mann-Whitney rank-sum test: $\mathrm{U}=32, \mathrm{Z}=-5.67, p<0.001)$. The reduction in postictal $\left[\mathrm{Cl}^{-}\right]_{\mathrm{i}}$ 

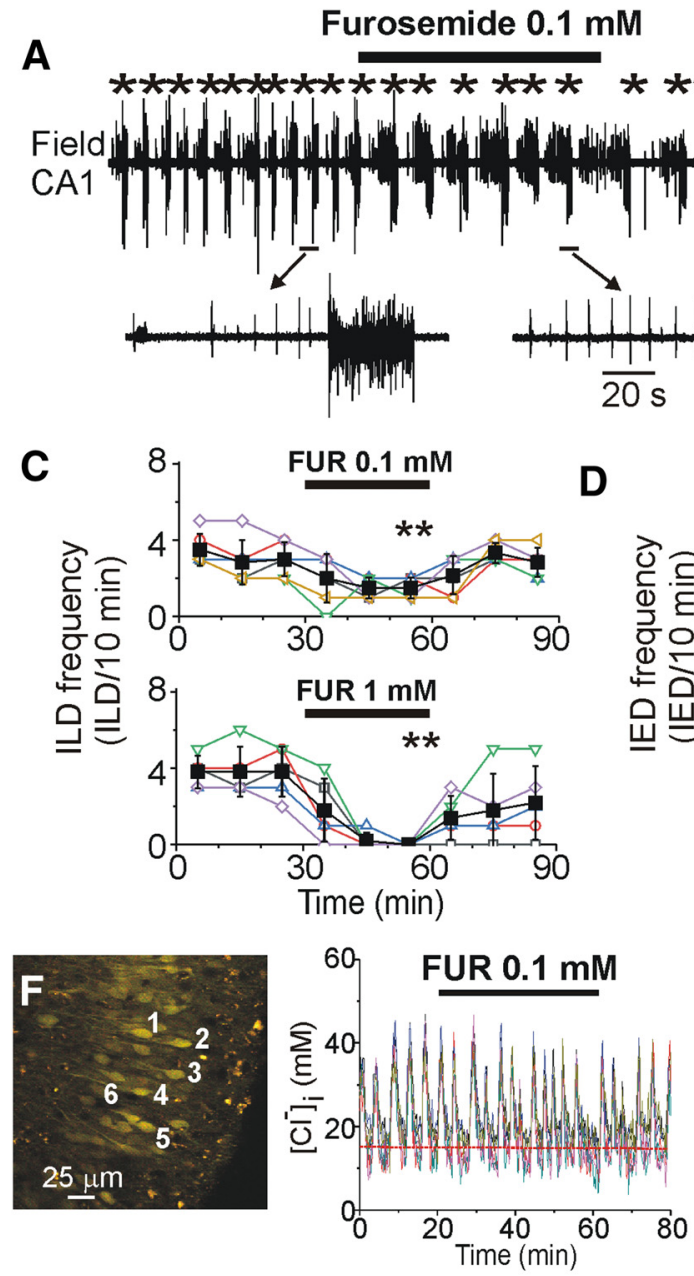
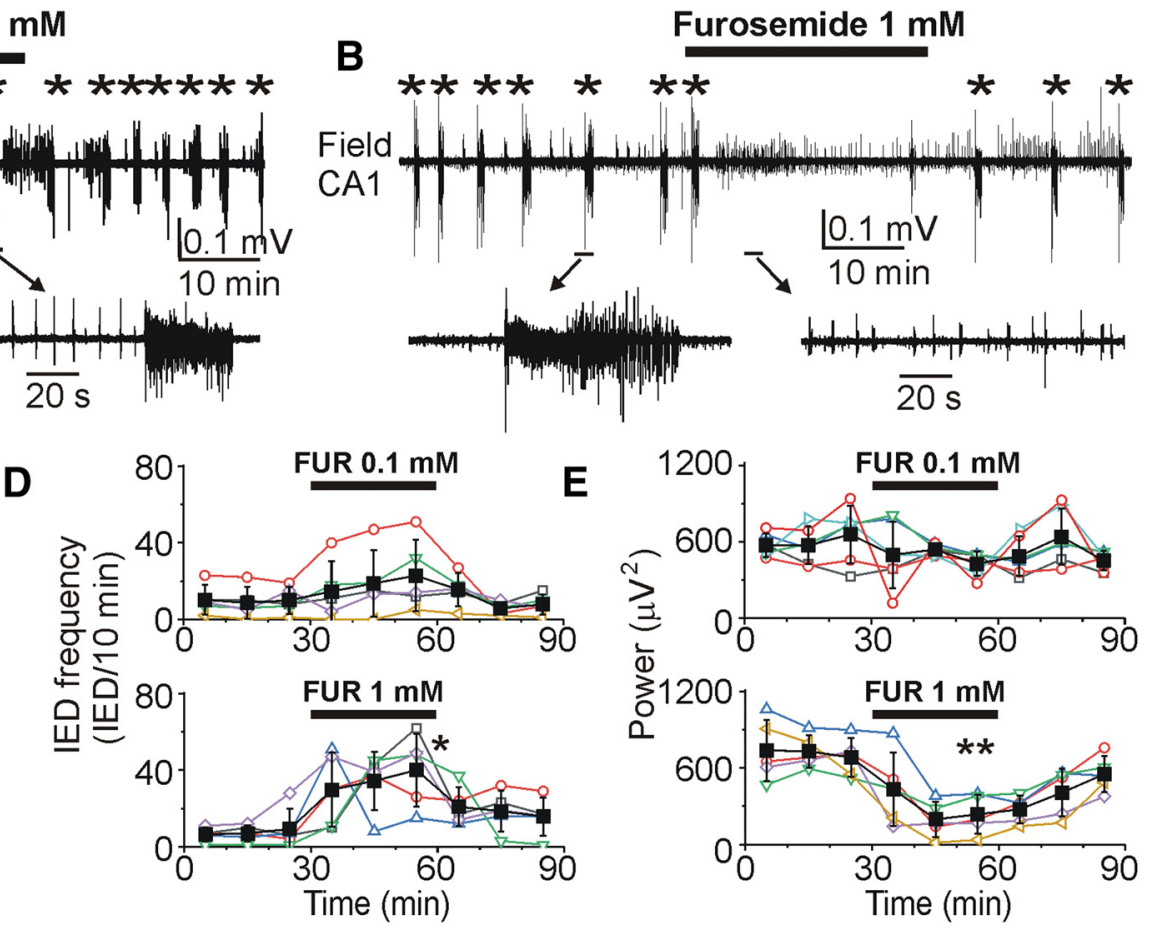
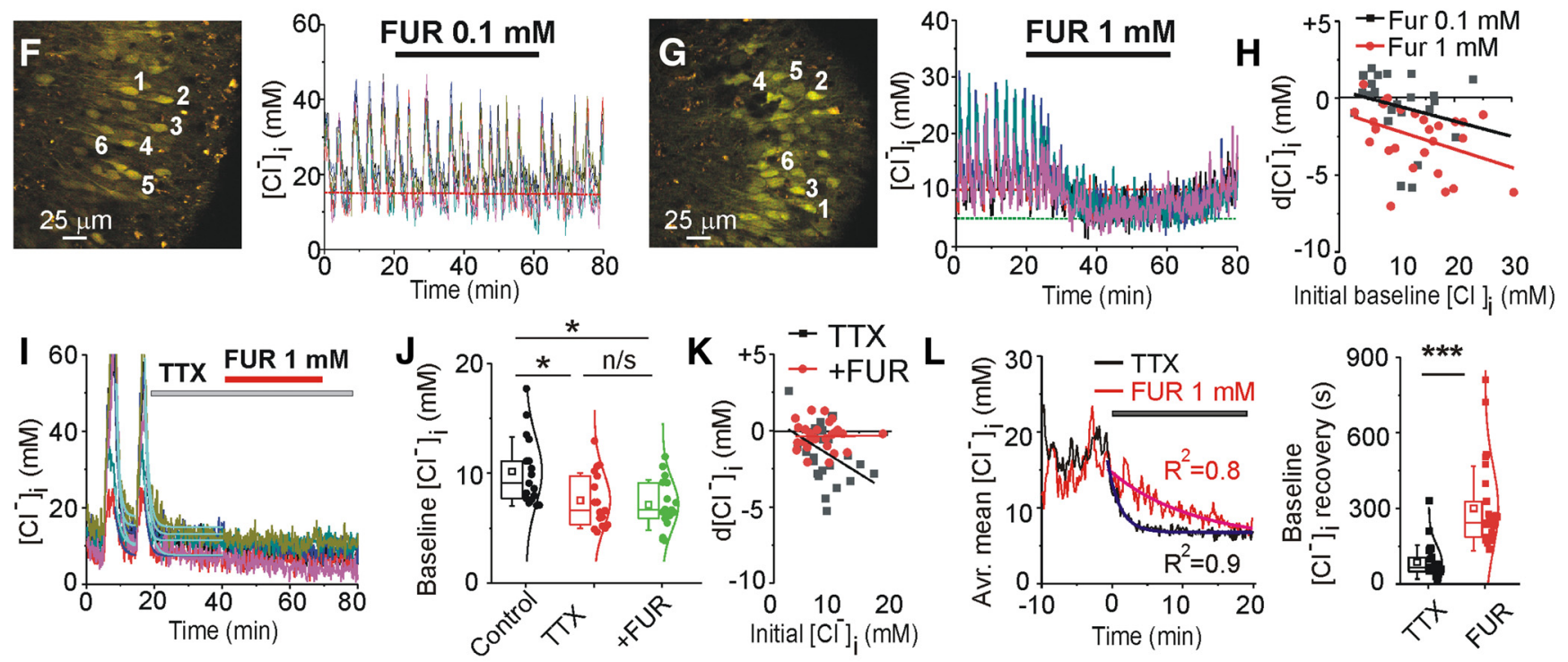

Figure 6. Effects of NKCC1/KCC2 blocker furosemide on recurrent epileptiform discharges and $\left[\mathrm{Cl}^{-}\right]_{\mathrm{i}}$. $\boldsymbol{A}, \boldsymbol{B}$, Extracellular field potential recording in the CA1 pyramidal cell layer in the organotypic hippocampal slice at DIV22 before (control), during and after application of furosemide $(0.1$ and $1 \mathrm{~mm}$ for $30 \mathrm{~min})$. $\boldsymbol{C}-\boldsymbol{E}$, Summary plots of the frequency of ILDs, IEDs, and power of corresponding activity in 10-min windows in individual slice cultures (open symbols). Filled symbols indicate mean \pm SD. Furosemide (0.1 mm) reduced the frequency of ILDs and increased the frequency of IEDs. Furosemide (1 mm) abolished recurrent ILDs, increased the frequency of IEDs, and significantly decreased the power of electrical activity ( ${ }^{*}$ corresponds to $p<0.05$; ${ }^{\star *} p<0.01$, paired sample $t$ test). $\boldsymbol{F}-\boldsymbol{H}$, Effects of furosemide $(0.1$ and $1 \mathrm{~mm})$ on $\left[\mathrm{Cl}^{-}\right]_{\mathrm{i}}$. Furosemide $(1 \mathrm{~mm})$ abolished recurrent ILDs and corresponding $\left[\mathrm{Cl}^{-}\right]_{\mathrm{i}}$ transients, and progressively reduced the baseline $\left[\mathrm{Cl}^{-}\right]_{\mathrm{i}} . \boldsymbol{H}$, Baseline $\left[\mathrm{Cl}^{-}\right]_{\mathrm{i}}$ changes in the presence of $0.1 \mathrm{~mm}$ furosemide and $1 \mathrm{~mm}$ furosemide as a function of an initial baseline $\left[\mathrm{Cl}^{-}\right]_{\mathrm{i}} . \mathbf{I}-\boldsymbol{K}$, Effects of TTX $(1 \mu \mathrm{M})$ and furosemide $(1 \mathrm{~mm})$ in the presence of $\mathrm{TTX}$ on $\left[\mathrm{Cl}^{-}\right]_{\mathrm{i}}$. TTX rapidly abolished chloride transients, reduced the median baseline $\left[\mathrm{Cl}^{-}\right]_{\mathrm{i}}{ }^{*} p<0.05$ compared with control, Friedman RM ANOVA on ranks, Tukey's test) and prevented effects of furosemide on $\left[\mathrm{Cl}^{-}\right]_{\mathrm{i}}(p>0.05$ compared with $T \mathrm{TX}) . \boldsymbol{L}, \mathrm{Averaged}$ mean $\left[\mathrm{Cl}^{-}\right]_{\mathrm{i}}$ changes before and after applications of TTX (black) or furosemide (red). Data were fitted with exponential fit to calculate decay time of $\left[\mathrm{Cl}^{-}\right]_{\mathrm{i}}$ extrusion during suppression of ILDs. Box (left) + data (right) plots correspond to median (25-75\%) $\left[\mathrm{Cl}^{-}\right]_{\mathrm{i}}$ in paired cells (filled circles) and their distribution curves; open squares and whisker range indicate mean \pm SD. Furosemide significantly delayed chloride extrusion during suppression of ILDs ${ }^{\star \star \star} p<0.001$; Mann-Whitney rank-sum test). 

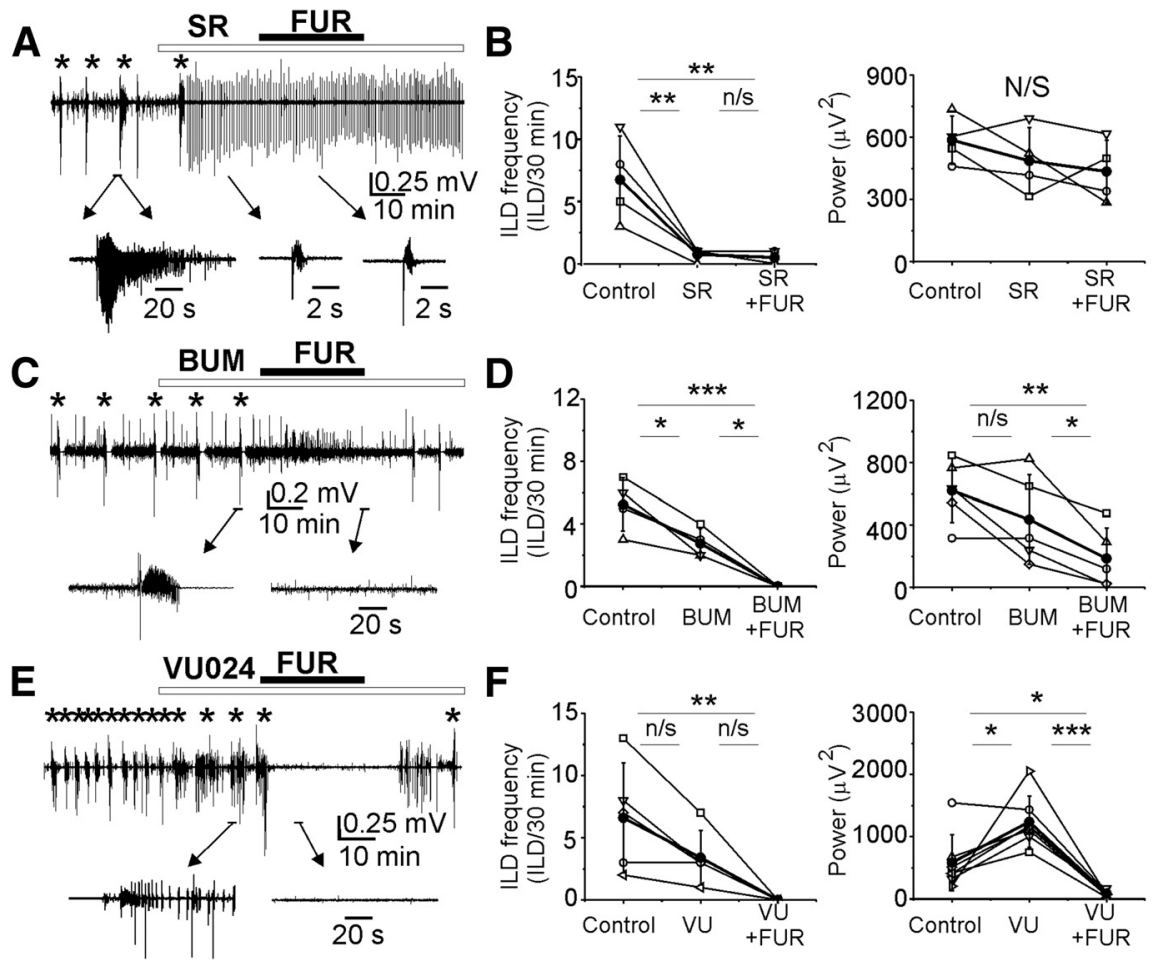

Figure 7. $\mathrm{GABA}_{\mathrm{A}}$ receptor-dependent anti-ictal effects of furosemide was enhanced in the presence of NKCC1 and KCC2 antagonists. $\boldsymbol{A}, \boldsymbol{C}, \boldsymbol{E}$, Extracellular field potential recordings in the CA1 pyramidal cell layer in the organotypic hippocampal slices in vitro. Furosemide (1 mM) was applied in the presence of $(\boldsymbol{A}) \mathrm{GABA}_{\mathrm{A}}$ receptor antagonist SR95531 (10 $\left.\mu \mathrm{M}\right),(\boldsymbol{C})$ NKCC1 blocker bumetanide $(10 \mu \mathrm{M})$, and $(\boldsymbol{E}) \mathrm{KCC} 2$ blocker VU0240551 (10 $\mu \mathrm{M})$. $\boldsymbol{A}, \boldsymbol{B}$, SR95531 abolished recurrent ILDs, induced hypersynchronous interictal bursts, and prevented the anti-ictal effect of furosemide. $\boldsymbol{C}, \boldsymbol{D}$, Furosemide potentiated anticonvulsant effect of bumetanide (10 $\mu \mathrm{m})$. $\boldsymbol{E}, \boldsymbol{F}$, Furosemide in the presence of VU0240551 abolished ictal and IEDs. B, D, $\boldsymbol{F}$, Corresponding summary data of the frequency of recurrent ILDs and power of electrical activity before and during drugs applications. Anti-ictal effects of furosemide were significant in the presence of bumetanide $(\boldsymbol{D})$ and VU0240551 (F). $N=5-6$ slices in each group of experiments; ${ }^{*} p<0.05$, ${ }^{* *} p<0.01$, ${ }^{* \star *} p<0.001$; one-way RM ANOVA, Tukey's test.

extrusion by high concentrations of furosemide was greater than the reduction induced by the KCC2-specific blocker VU0463271 (Fig. 3H). These data also suggest that the antiictal effects of high concentrations of furosemide are because of interactions with an unidentified $\mathrm{Cl}^{-}$transporter, exchanger, or channel.

We next used pharmacological tools to determine whether $\mathrm{GABA}_{A}-\mathrm{R}$ and $\mathrm{CCC}$ (NKCC1 and KCC2) inhibitors prevent the anti-ictal effects of furosemide (Fig. 7). Under similar experimental conditions, bath application of furosemide $(1 \mathrm{~mm})$ in the presence of the $\mathrm{GABA}_{\mathrm{A}}$ receptor antagonist SR95531 $(10 \mu \mathrm{M})$ did not change the mean frequency of epileptiform discharges $(N=4$ slices; one-way RM ANOVA: $D F=11, F=15.7, p=0.004$; Tukey's test: control compared with SR95531, df $=6, q=6.71, p=0.008$; control vs furosemide in the presence of SR95531, $\mathrm{df}=6.25, q=6.99, p=0.006$; SR95531 vs furosemide in the presence of SR95531, $\mathrm{df}=0.25, q=0.28, p=0.979$; Fig. $7 A, B$ ) and the mean power of epileptiform discharges (oneway RM ANOVA: $\mathrm{DF}=11, F=1.48, p=0.29$ ). In contrast, furosemide $(1 \mathrm{~mm})$ strongly enhanced the anticonvulsant action of bumetanide applied at a concentration (10 $\mu \mathrm{M})$ that selectively blocked NKCC1 (Fig. 7C,D). Initial application of bumetanide $(10 \mu \mathrm{M})$ significantly reduced the mean frequency of ILDs from $5.25 \pm 1.7$ to $2.75 \pm 0.96$ ILD/
$30 \mathrm{~min}$, and subsequent application of furosemide (1 $\mathrm{mm}$ ) in the presence of bumetanide abolished recurrent ILDs $(N=4$ slices; one-way RM ANOVA: $D F=11, F=30.1$, $p<0.001$; Tukey's test: control vs bumetanide, $\mathrm{df}=2.5$, $q=5.22, p=0.024$; control vs furosemide in the presence of bumetanide: $\mathrm{df}=5.25, q=10.9, p<0.001$; bumetanide vs furosemide in the presence of bumetanide: $d f=2.75$, $q=5.75, p=0.016$; Fig. $7 C, D)$. Corresponding power of electrical activity decreased from $620.9 \pm 206.3 \mu \mathrm{V}^{2}$ in control to $435.2 \pm 287.7 \mu \mathrm{V}^{2}$ during bumetanide application, and to $185.1 \pm 196.6 \mu \mathrm{V}^{2}$ during subsequent application of furosemide in the presence of bumetanide (one-way RM ANOVA: $D F=14, F=14.7, p=0.002$; Tukey's test: control vs bumetanide, $\mathrm{df}=185.7, q=3.26, p=0.113$; control vs furosemide in the presence of bumetanide: $\mathrm{df}=435.8$, $q=7.6, p=0.002$; bumetanide vs furosemide in the presence of bumetanide: $\mathrm{df}=250.1, q=4.39, p=0.035$; Fig. $7 C, D)$.

Under similar experimental conditions (DIV16-DIV19), bath application of the low-affinity KCC2 antagonist VU0240551 (10 $\mu \mathrm{m}$ for $30 \mathrm{~min}$ ) reduced the mean frequency of ILDs from $6.6 \pm 4.4$ to $3.4 \pm 2.2$ ILD/30 min and increased the frequency of IEDs, and consecutive application of furosemide $(1 \mathrm{~mm})$ in the presence of VU0240551 $(10 \mu \mathrm{M})$ rapidly abolished both ILDs and IEDs 
$(N=5$; one-way RM ANOVA: $\mathrm{DF}=14, F=10.61, p=0.006$; Tukey's test: control vs VU0240551, $\mathrm{df}=3.2, q=3.15$, $p=0.125$; control vs furosemide in the presence of VU0240551, $\mathrm{df}=6.6, q=6.514, p=0.005$; VU0240551 vs furosemide in the presence of VU0240551, df $=3.4$, $q=3.36, p=0.102$; Fig. $7 E, F)$. Corresponding power of electrical activity increased from $584.4 \pm 448.7 \mu \mathrm{V}^{2}$ in control to $1241 \pm 415.9 \mu \mathrm{V}^{2}$ during VU0240551 application, and consecutive application of furosemide $(1 \mathrm{mM})$ in the presence of VU0240551 $(10 \mu \mathrm{M})$ decreased the power of electrical activity to $87.7 \pm 44.6 \mu \mathrm{V}^{2}$ (one-way $\mathrm{RM}$ ANOVA: $D F=20, F=19.2, p<0.001$; Tukey's test: control vs VU0240551, $\mathrm{df}=-656.6, q=4.97, p=0.011$; control vs furosemide in the presence of VU0240551, $\mathrm{df}=496.7$, $q=3.76, p=0.041$; VU0240551 vs furosemide in the presence of VU0240551, $\mathrm{df}=1153.2, q=8.7, p<0.001$; Fig. $7 E, F)$. These results suggest that the anti-ictal action of furosemide requires functional $\mathrm{GABA}_{A}$ receptors, is independent of NKCC1 activity, and greatly exceeds the antiictal effects of specific blockers of KCC2 transport activity. Curiously, both bumetanide and VU0240551 strongly potentiated the antiepileptic action of furosemide. These results are consistent with anti-ictal effects arising from interactions with an unidentified $\mathrm{Cl}$ transporter, exchanger, or channel.

\section{Effects of KCC2 cotransporter enhancer CLP257 on $\left[\mathrm{Cl}_{\mathrm{i}}\right]_{\mathrm{i}}$ and recurrent ILDs}

Enhancing KCC2 transport activity may be a useful therapeutic strategy to restore and/or reduce a baseline $\left[\mathrm{Cl}^{-}\right]_{\mathrm{i}}$, improve GABAergic inhibition, suppress ILDs and prevent epileptogenesis (Gagnon et al., 2013; Moore et al., 2018). We therefore determined the acute anticonvulsant efficacy of the putative KCC2 activator CLP 257 (1$30 \mu \mathrm{m}$; Gagnon et al., 2013) and its effects on neuronal $\left[\mathrm{Cl}^{-}\right]_{\mathrm{i}}$ in the organotypic hippocampal slices model of epileptogenesis in vitro.

CLP257 at low concentration ( $1 \mu \mathrm{m}$ for $60 \mathrm{~min}$ ) non-significantly decreased the mean frequency of ILDs from $5 \pm 3.4$ to $2.8 \pm 2 \mathrm{ILD} / 20 \mathrm{~min}(N=6$ slices at DIV14-DIV20; paired sample $t$ test, $t=1.73$, df $=5, p=0.14$; Fig. $8 A, C$ ) and significantly reduced the group mean duration of ILDs from $0.66 \pm 0.3$ to $0.41 \pm 0.26 \mathrm{~min}$ (paired sample $t$ test, $t=4.19, \mathrm{df}=5, p=0.008$; Fig. $8 D$ ). The net effect of the changes in extracellular field potential activity was a decrease in the mean power in 20-min windows from $382.1 \pm 125.3$ to $293.9 \pm 80.3 \mu \mathrm{V}^{2}$ (paired sample $t$ test, $t=2.42, \mathrm{df}=5, p=0.059$; Fig. $8 E$ ). CLP257 at high concentration (30 $\mu \mathrm{M}$ for $60 \mathrm{~min})$ significantly decreased the mean frequency of ILDs from $5.67 \pm 2.5$ to $2.67 \pm 1.63$ ILD/20 $\min (N=6$ slices at DIV15-DIV20; paired sample $t$ test, $t=3.5$, $\mathrm{df}=5, p=0.017$; Fig. $8 B, C)$ and reduced the group mean duration of ILDs from $0.83 \pm 0.57$ to $0.59 \pm 0.3$ min (paired sample $t$ test, $t=1.3, \mathrm{df}=5, p=0.25$; Fig. $8 D$ ). These changes resulted in a significant net decrease in the mean power of electrical activity in 20-min windows from $738.5 \pm 171.3$ to $380.2 \pm 147.8 \mu \mathrm{V}^{2}$ (paired sample $t$ test, $t=11.5, \mathrm{df}=4, p<0.001 ;$ Fig. $8 E$ ). In contrast to these effects of CLP257 on spontaneous epileptiform activity, a higher concentration of CLP257 $(100 \mu \mathrm{M})$ increased the duration of
ILDs in the 4-AP-induced model of epileptogenesis (Hamidi and Avoli, 2015), suggesting non-specific effects at higher concentrations of CLP257.

We next determined the effects of CLP257 on baseline $\left[\mathrm{Cl}^{-}\right]_{\mathrm{i}}$ and the postictal decay time constant of $\left[\mathrm{Cl}^{-}\right]_{\mathrm{i}}$ extrusion during recurrent ILDs (Fig. 8F-l). Bath application of CLP257 (1 $\mu \mathrm{M}$ for 30-40 min) induced a significant reduction in the median baseline $\left[\mathrm{Cl}^{-}\right]_{\mathrm{i}}$ between ILDs from 13.1 $(10.3-16.1) \pm 5.8$ to $11.9(8.8-15) \pm 7.2 \mathrm{~mm}(N=5$ slices, $n=30$ paired cells; Wilcoxon signed-rank test: $W=308$, $Z=2.38, p=0.017$; Fig. 8G,H). In addition, CLP257 (1 $\mu \mathrm{M})$ significantly reduced the median decay time constant of $\mathrm{Cl}^{-}$extrusion during postictal recovery of baseline $\left[\mathrm{Cl}^{-}\right]_{\mathrm{i}}$ from 34.95 (16.87-58.15) \pm 25.14 to $23.6(7.89-40.65) \pm$ $22.16 \mathrm{~s}$ (Wilcoxon signed-rank test: $W=238, Z=2.5$, $p=0.012$; Fig. 8/). This reduction was correlated with a reduced duration of recurrent ILDs (Fig. $8 A, D$ ).

In conclusion, our results demonstrated that low concentration of CLP257 $(1 \mu \mathrm{M})$ modestly improved $\left[\mathrm{Cl}^{-}\right]_{\mathrm{i}}$ homeostasis and reduced the duration of recurrent ILDs. However, CLP257 $(1 \mu \mathrm{M})$ did not change the frequency of recurrent ILDs. In contrast, CLP257 at high concentration $(30 \mu \mathrm{M})$ significantly reduced the frequency of ILDs and power of electrical activity.

\section{Discussion}

\section{Summary of findings}

In an in vitro preparation exhibiting spontaneous electrographic interictal spikes and ILDs, we found two important effects that were clearly not related to CCCs: (1) $\mathrm{GABA}_{\mathrm{A}}$ receptor antagonists blocked ILDs and produced high-amplitude periodic inter-ILDs; (2) blocking ILDs reduced the baseline (steady state) $\left[\mathrm{Cl}^{-}\right]_{\mathrm{i}}$ independently of effects on CCCs. Manipulation of cation-chloride cotransport in this preparation with currently available pharmacological agents demonstrated: (3) antagonizing KCC2 activity prolonged the ictal increase in $\left[\mathrm{Cl}^{-}\right]_{\mathrm{i}} ;$ (4) antagonizing KCC2 activity increased ILD duration; (5) increasing $\mathrm{KCC} 2$ activity reduced the ictal $\left[\mathrm{Cl}^{-}\right]_{\mathrm{i}}$ increase; (6) increasing KCC2 activity reduced ILD durations; (7) the effects of high-affinity KCC2 modulators were dependent on the activity of GABA $A_{A}$ receptors; however, (8) the effects of the high-affinity $\mathrm{KCC} 2$ antagonist VU0463271 on $\left.\mathrm{CCl}^{-}\right]_{i}$ and ILDs were only apparent at concentrations 20 times higher than the $\mathrm{IC}_{50}(61 \mathrm{nM})$ for KCC2 block established in dissociated cell cultures; (9) the effects of the KCC2 enhancer CLP257 on $\left[\mathrm{Cl}^{-}\right]_{\mathrm{i}}$ and ILDs were evident at two times the $\mathrm{EC}_{50}(616 \mathrm{~nm})$ for KCC2 enhancement.

We also found evidence of effects of CCC antagonists that were not mediated by KCC2 or NKCC1. The largest of these effects was the profound $\mathrm{GABA}_{\mathrm{A}}$ receptor-dependent anti-ictal effect of high concentrations of furosemide (Hochman et al., 1995; Gutschmidt et al., 1999; Haglund and Hochman, 2005; Blauwblomme et al., 2018) that was enhanced in the presence of NKCC1 and KCC2 antagonists (Fig. 7). This effect was correlated with a prolongation of the postictal $\left[\mathrm{Cl}^{-}\right]_{\mathrm{i}}$ transient that greatly exceeded the maximum effect of specific CCC blockers. These findings raise the possibility that blockade of an unidentified CCC, 

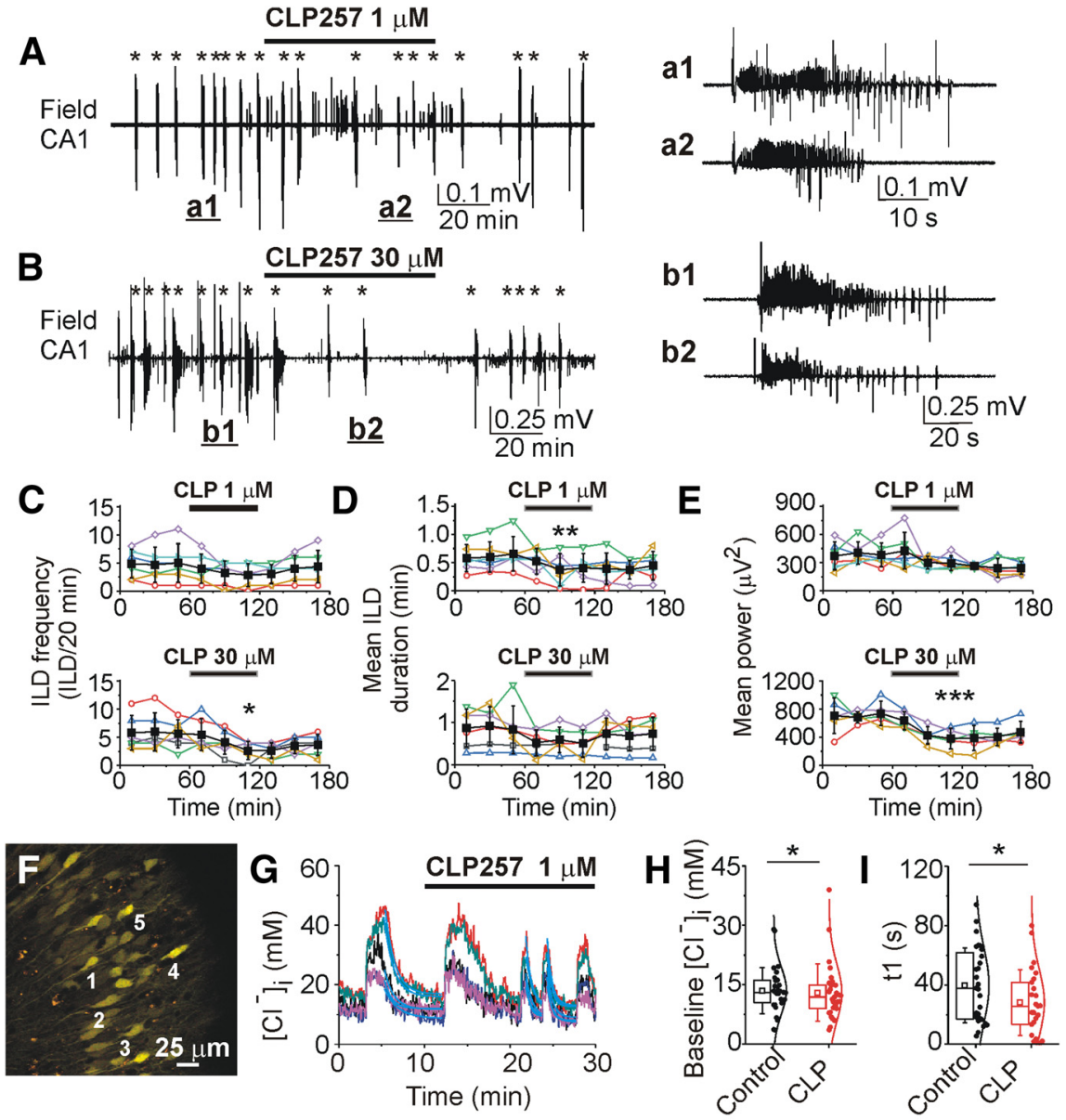

Figure 8. The KCC2 enhancer CLP257 reduced duration of ILDs. A, B, Extracellular field potential recordings in the CA1 pyramidal cell layer before (control), during and after application of CLP257 (1 and $30 \mu \mathrm{M}$ for $1 \mathrm{~h}$ ). Examples of ictal-like events in control and during application of $1 \mu \mathrm{M}$ CLP257 (A, a1, a2) and $30 \mu \mathrm{M}$ CLP257 (B, b1, b2). $\boldsymbol{C}-\boldsymbol{E}$, Summary plots of the frequency and mean duration of ILDs, and power of electrical activity in individual slices (open symbols) and corresponding group mean \pm SD (filled symbols) before, during and after $1 \mu \mathrm{M}$ (top plots) and $30 \mu \mathrm{M}$ (bottom plots) CLP257 applications. CLP257 (1 $\mu \mathrm{M})$ significantly reduced the mean duration of ILDs ( ${ }^{*} p<0.05$, ${ }^{* *} p<0.01,{ }^{* \star *} p<0.001$; paired sample $t$ test). $\boldsymbol{F}$, Effects of CLP257 on [Cl']; as a function of time in $n=5$ individual cell. $\boldsymbol{G}, \boldsymbol{H}$, Statistical histograms showing the effects of CLP257 $(1 \mu \mathrm{M})$ on baseline $\left[\mathrm{Cl}^{-}\right]_{\mathrm{i}}$ and decay time of chloride extrusion $\left({ }^{*} p<0.05\right.$, Wilcoxon signed-rank test). CLP257 (1 $\mu \mathrm{M})$ significantly accelerated extrusion rate (t1) of neuronal chloride during recurrent ILDs.

perhaps KCC3, mediates these remarkable anticonvulsant effects, but it is equally possible that the anticonvulsant effects are not related to the reduced $\mathrm{Cl}^{-}$transport. Rather, other nonspecific effects (Andreasen and Nedergaard, 2017) may be responsible for this profound anticonvulsant effect, for example, interference with vesicular glutamate uptake (Roseth et al., 1995), or other membrane $\mathrm{Cl}^{-}$exchangers or channels, particularly $\mathrm{GABA}_{\mathrm{A}}$ receptor-operated channels in light of our first finding (Korpi and Lüddens, 1997; Mtchedlishvili and Kapur, 2006).

\section{The role of $\mathrm{KCC} 2$ transport activity in termination of ILDs}

Activity-dependent neuronal $\mathrm{Cl}^{-}$accumulation and a consequent transient depolarizing shift in the reversal potential of the $G A B A_{A}-R\left(E_{G A B A}\right)$ have been suggested to contribute to generation of ictal-clonic afterdischarges (Fujiwara-Tsukamoto et al., 2006, 2010; Ellender et al., 2014). We determined the role of KCC2 transport activity in extrusion of neuronal $\mathrm{Cl}^{-}$and termination of ictal-like tonic-clonic activity using pharmacological inhibition of KCC2 transport activity. Our data demonstrated that the high-affinity KCC2 inhibitor VU0463271 increased ILD-induced $\left[\mathrm{Cl}^{-}\right]_{i}$ elevation and the duration of ILDs (Fig. 3). Neuronal baseline $\mathrm{Cl}^{-}$remained elevated during prolonged ictal-like activity and the mean decay time of chloride extrusion increased from the mean $21.4 \pm 7.6 \mathrm{~s}$ in control to $188.1 \pm 111 \mathrm{~s}$ in the presence of VU04663271. The sodium channel blocker TTX in the presence of VU0463271 abolished recurrent ILDs and recovered baseline $\left[\mathrm{Cl}^{-}\right]_{\mathrm{i}}$ within the mean $185.5 \pm 67.2 \mathrm{~s}$. In addition, VU0463271 application in the presence of TTX did not significantly change the mean baseline $\left[\mathrm{Cl}^{-}\right]_{\text {i. Our results }}$ demonstrate that KCC2 transport activity efficiently recovers $\mathrm{E}_{\mathrm{CI}}$ during ILDs, restores GABAergic inhibition and these effects are correlated with more rapid termination of ILDs. Inhibition of KCC2 transport activity delays chloride extrusion rate suggesting that impaired KCC2 function may contribute to the transition from the short ictal-like events to sustained SE. 


\section{Modulation of CCCs for control of drug-resistant ILDs}

Neuronal chloride concentration $\left(\left[\mathrm{Cl}^{-}\right]_{\mathrm{i}}\right)$ is an important determinant of both postsynaptic $\mathrm{GABA}_{\mathrm{A}}$-receptor-mediated signaling and cell volume regulation. $\mathrm{Cl}^{-}$equilibrium is mediated by a Donnan system that includes intra and extracellular impermeant anions, and in which the CCCs comprise the requisite cation and chloride membrane permeability (Glykys et al., 2017). Increasing this permeability by increasing the maximum velocity of cation-chloride cotransport should not change the baseline $\left[\mathrm{Cl}^{-}\right]_{\mathrm{i}}$. However, increasing the maximum velocity of transport could increase the ability of neurons to buffer synaptically-mediated $\mathrm{Cl}^{-}$influx. Importantly, this increased ability is predicated on the extracellular potassium; increases in extracellular potassium directly alter the steady state $\left[\mathrm{Cl}^{-}\right]_{\mathrm{i}}$.

The maximum velocity of CCCs is regulated by a system of the WNK-SPAK/OSR1 kinase complex pathways [serine-threonine kinase WNK (with no lysine) and SPS1related proline/alanine-rich kinase (SPAK) or the SPAK homolog oxidative stress-responsive kinase 1 (OSR1)] that result in the compensatory phosphorylation and dephosphorylation processes (Kahle et al., 2006; Melo et al., 2013; Alessi et al., 2014; de Los et al., 2014). In immature neurons and isotonic conditions $\mathrm{KCC} 2$ is phosphorylated at two C-terminal threonine (Thr906 and Thr1007) and inactive, whereas CNS development and hypotonic conditions promote their dephosphorylation and activation (Kahle et al., 2013; Pisella et al., 2019; Watanabe et al., 2019).

Traumatic injury to the brain alters the equilibrium value of chloride, resulting in an elevated baseline $\left[\mathrm{Cl}^{-}\right]_{\mathrm{i}}$ and depolarizing shift in $\mathrm{E}_{\mathrm{GABA}}$ (van den Pol et al., 1996; Pond et al., 2006; Kahle et al., 2008; Blaesse et al., 2009; Dzhala et al., 2010, 2012). Acute brain injury results in cytotoxic edema, in which there is a net neuronal uptake of chloride salts and water. Suppressing CCC activity may be a useful therapeutic strategy in this condition to prevent $\left[\mathrm{Cl}^{-}\right]_{\mathrm{i}}$ accumulation, reduce $\left[\mathrm{Cl}^{-}\right]_{\mathrm{i}}$ and swelling in injured neurons, restore GABAergic inhibition and suppress acute ILDs (Kahle et al., 2008; Gagnon et al., 2013; Glykys et al., 2017). Previous studies in in vitro and in vivo models of hypoxia-ischemia, recurrent seizures and neuronal brain injury demonstrated that inhibition of NKCC1 reduced $\left[\mathrm{Cl}^{-}\right]_{\mathrm{i}}$ in injured neurons, enhanced GABAergic inhibition and enhanced efficacy of GABAergic anticonvulsants (Dzhala et al., 2005, 2008, 2012; Pond et al., 2006; Nardou et al., 2009, 2011; Cleary et al., 2013; Dzhala and Staley, 2015; Sivakumaran and Maguire, 2016).

In the current study, we investigated the role of CCC inhibitors in chronic epilepsy in vitro rather than seizures in the setting of acute brain injury in vivo. Studies in acute brain slice preparations from patients with chronic epilepsy have supported the acute efficacy of bumetanide (Pallud et al., 2014). However, in acute brain slices, there is also a significant degree of acute brain injury (Dzhala et al., 2012), making it difficult to separate effects because of acute versus chronic changes. We found only $\mathrm{GABA}_{\mathrm{A}}$ receptor-dependent pro-ictal effects of KCC2 antagonists at concentrations that also prolonged ictal $\left[\mathrm{Cl}^{-}\right]_{\mathrm{i}}$ transients. This is consistent with the idea that reducing KCC2 activity degrades $\mathrm{Cl}^{-}$homeostasis and the ability to restore $\left.\mathrm{Cl}^{-}\right]_{\mathrm{i}}$ and the proper polarity of $\mathrm{GABA}_{\mathrm{A}}$ signaling after synaptic activity. KCC2 antagonists have a potential anti-ictal effect in their reduction of $\left[\mathrm{K}^{+}\right]_{0}$ transients. We did not find evidence for an anti-ictal effect, but our slice cultures were perfused via the bath rather than via the vasculature, so it is possible that bulk ACSF flow reduced this potential anti-ictal effect on $\mathrm{KCC} 2$-dependent $\left[\mathrm{K}^{+}\right]_{0}$ accumulation (Viitanen et al., 2010).

There is substantial interest in overexpression and enhancement of KCC2 transport activity as a novel therapeutic strategy to improve synaptic GABAergic inhibition in neurologic disorders (Kahle et al., 2008; Gagnon et al., 2013; Moore et al., 2018; Magloire et al., 2019). Highthroughput screening identified a new high-affinity compound CLP257 $\left(\mathrm{EC}_{50}=616 \mathrm{~nm}\right)$ and its carbamate prodrug derivative CLP290 that selectively activates KCC2 over other KCC family members, NKCC1 and $\mathrm{GABA}_{\mathrm{A}}$ receptors (Gagnon et al., 2013). CLP257 restored impaired $\mathrm{Cl}^{-}$transport in adult spinal cord slices with impaired KCC2 function, restored $\mathrm{Cl}^{-}$extrusion and renormalized stimulus-evoked responses in adult neurons in an experimental model of neuropathic pain. However, the pharmacodynamic profile of CLP257, including KCC2 specificity and mode of action, has not been determined. High concentrations of CLP257 (30-50 $\mu \mathrm{M})$ was reported to potentiate $\mathrm{GABA}_{\mathrm{A}}$ receptors (Cardarelli et al., 2017). Even higher concentrations of CLP257 $(100 \mu \mathrm{M})$ increased the duration of ILDs without affecting their frequency (Hamidi and Avoli, 2015).

We investigated whether enhancing KCC2 transport activity with a low concentration of CLP257 affects baseline $\left[\mathrm{Cl}^{-}\right]_{\mathrm{i}}$ and $\left[\mathrm{Cl}^{-}\right]_{\mathrm{i}}$ extrusion rates in injured neurons during ictal-like events, and the downstream effects on frequency and duration of recurrent ILDs in the organotypic hippocampal slice in vitro model of epileptogenesis (Fig. 8). We found that low concentrations of CLP257 (1 $\mu \mathrm{M})$ improved $\left[\mathrm{Cl}^{-}\right]_{i}$ homeostasis, increased postictal $\left[\mathrm{Cl}^{-}\right]_{i}$ extrusion rates, and modestly reduced ictal duration without effecting ictal frequency. Our data suggest that the modest anticonvulsant actions of low dose CLP257 are likely partially mediated by enhanced KCC2 transport activity that more efficiently restores neuronal baseline $\mathrm{Cl}^{-}$during termination of ictal-like events. In addition, our data validate CLP257 as a promising target of investigation for antiepileptic therapy and highlight the ongoing need to develop more specific activators of KCC2 cotransport.

\section{References}

Alessi DR, Zhang J, Khanna A, Hochdörfer T, Shang Y, Kahle KT (2014) The WNK-SPAK/OSR1 pathway: master regulator of cation-chloride cotransporters. Sci Signal 7:re3.

Andreasen M, Nedergaard S (2017) Furosemide depresses the presynaptic fiber volley and modifies frequency-dependent axonal excitability in rat hippocampus. J Neurophysiol 117:1512-1523.

Berdichevsky Y, Dzhala V, Mail M, Staley KJ (2012) Interictal spikes, seizures and ictal cell death are not necessary for post-traumatic epileptogenesis in vitro. Neurobiol Dis 45:774-785.

Berglund K, Schleich W, Wang H, Feng G, Hall WC, Kuner T, Augustine GJ (2008) Imaging synaptic inhibition throughout the 
brain via genetically targeted Clomeleon. Brain Cell Biol 36:101118.

Blaesse P, Airaksinen MS, Rivera C, Kaila K (2009) Cation-chloride cotransporters and neuronal function. Neuron 61:820-838.

Blauwblomme T, Dzhala V, Staley K (2018) Transient ischemia facilitates neuronal chloride accumulation and severity of seizures. Ann Clin Transl Neurol 5:1048-1061.

Cardarelli RA, Jones K, Pisella LI, Wobst HJ, McWilliams LJ, Sharpe PM, Burnham MP, Baker DJ, Chudotvorova I, Guyot J, Silayeva L, Morrow DH, Dekker N, Zicha S, Davies PA, Holenz J, Duggan ME, Dunlop J, Mather RJ, Wang Q, et al. (2017) The small molecule CLP257 does not modify activity of the $\mathrm{K}(+)-\mathrm{Cl}(-)$ co-transporter KCC2 but does potentiate GABAA receptor activity. Nat Med 23:1394-1396.

Cleary RT, Sun H, Huynh T, Manning SM, Li Y, Rotenberg A, Talos DM, Kahle KT, Jackson M, Rakhade SN, Berry GT, Berry G, Jensen FE (2013) Bumetanide enhances phenobarbital efficacy in a rat model of hypoxic neonatal seizures. PLoS One 8:e57148.

de Los HP, Alessi DR, Gourlay R, Campbell DG, Deak M, Macartney TJ, Kahle KT, Zhang J (2014) The WNK-regulated SPAK/OSR1 kinases directly phosphorylate and inhibit the $\mathrm{K}+-\mathrm{Cl}$ - co-transporters. Biochem J 458:559-573.

Delpire E, Staley KJ (2014) Novel determinants of the neuronal $\mathrm{Cl}(-)$ concentration. J Physiol 592:4099-4114.

Delpire E, Baranczak A, Waterson AG, Kim K, Kett N, Morrison RD, Daniels JS, Weaver CD, Lindsley CW (2012) Further optimization of the K-Cl cotransporter KCC2 antagonist ML077: development of a highly selective and more potent in vitro probe. Bioorg Med Chem Lett 22:4532-4535.

Duy PQ, David WB, Kahle KT (2019) Identification of KCC2 mutations in human epilepsy suggests strategies for therapeutic transporter modulation. Front Cell Neurosci 13:515.

Dyhrfjeld-Johnsen J, Berdichevsky Y, Swiercz W, Sabolek H, Staley KJ (2010) Interictal spikes precede ictal discharges in an organotypic hippocampal slice culture model of epileptogenesis. J Clin Neurophysiol 27:418-424.

Dzhala VI, Staley KJ (2003) Excitatory actions of endogenously released GABA contribute to initiation of ictal epileptiform activity in the developing hippocampus. J Neurosci 23:1840-1846.

Dzhala V, Staley KJ (2015) Acute and chronic efficacy of bumetanide in an in vitro model of posttraumatic epileptogenesis. CNS Neurosci Ther 21:173-180.

Dzhala VI, Talos DM, Sdrulla DA, Brumback AC, Mathews GC, Benke TA, Delpire E, Jensen FE, Staley KJ (2005) NKCC1 transporter facilitates seizures in the developing brain. Nat Med 11:1205-1213.

Dzhala VI, Brumback AC, Staley KJ (2008) Bumetanide enhances phenobarbital efficacy in a neonatal seizure model. Ann Neurol 63:222-235.

Dzhala VI, Kuchibhotla KV, Glykys JC, Kahle KT, Swiercz WB, Feng G, Kuner T, Augustine GJ, Bacskai BJ, Staley KJ (2010) Progressive NKCC1-dependent neuronal chloride accumulation during neonatal seizures. J Neurosci 30:11745-11761.

Dzhala V, Valeeva G, Glykys J, Khazipov R, Staley K (2012) Traumatic alterations in GABA signaling disrupt hippocampal network activity in the developing brain. J Neurosci 32:4017-4031.

Ellender TJ, Raimondo JV, Irkle A, Lamsa KP, Akerman CJ (2014) Excitatory effects of parvalbumin-expressing interneurons maintain hippocampal epileptiform activity via synchronous afterdischarges. J Neurosci 34:15208-15222.

Fujiwara-Tsukamoto Y, Isomura Y, Takada M (2006) Comparable GABAergic mechanisms of hippocampal seizurelike activity in posttetanic and low-Mg2 + conditions. J Neurophysiol 95:20132019.

Fujiwara-Tsukamoto Y, Isomura Y, Imanishi M, Ninomiya T, Tsukada M, Yanagawa Y, Fukai T, Takada M (2010) Prototypic seizure activity driven by mature hippocampal fast-spiking interneurons. J Neurosci 30:13679-13689.

Fung FW, Jacobwitz M, Vala L, Parikh D, Donnelly M, Xiao R, Topjian AA, Abend NS (2019) Electroencephalographic seizures in critically ill children: management and adverse events. Epilepsia 60:20952104.

Gagnon M, Bergeron MJ, Lavertu G, Castonguay A, Tripathy S, Bonin RP, Perez-Sanchez J, Boudreau D, Wang B, Dumas L, Valade I, Bachand K, Jacob-Wagner M, Tardif C, Kianicka I, Isenring P, Attardo G, Coull JA, De Koninck Y (2013) Chloride extrusion enhancers as novel therapeutics for neurological diseases. Nat Med 19:1524-1528.

Gamba G (2005) Molecular physiology and pathophysiology of electroneutral cation-chloride cotransporters. Physiol Rev 85:423493.

Glykys J, Dzhala VI, Kuchibhotla KV, Feng G, Kuner T, Augustine G, Bacskai BJ, Staley KJ (2009) Differences in cortical versus subcortical GABAergic signaling: a candidate mechanism of electroclinical uncoupling of neonatal seizures. Neuron 63:657-672.

Glykys J, Dzhala V, Egawa K, Balena T, Saponjian Y, Kuchibhotla KV, Bacskai BJ, Kahle KT, Zeuthen T, Staley KJ (2014) Local impermeant anions establish the neuronal chloride concentration. Science 343:670-675.

Glykys J, Dzhala V, Egawa K, Kahle KT, Delpire E, Staley K (2017) Chloride dysregulation, seizures, and cerebral edema: a relationship with therapeutic potential. Trends Neurosci 40:276-294.

González OC, Krishnan GP, Chauvette S, Timofeev I, Sejnowski T, Bazhenov M (2015) Modeling of age-dependent epileptogenesis by differential homeostatic synaptic scaling. J Neurosci 35:1344813462.

Gutschmidt KU, Stenkamp K, Buchheim K, Heinemann U, Meierkord $\mathrm{H}$ (1999) Anticonvulsant actions of furosemide in vitro. Neuroscience 91:1471-1481.

Haglund MM, Hochman DW (2005) Furosemide and mannitol suppression of epileptic activity in the human brain. J Neurophysiol 94:907-918.

Hamidi S, Avoli M (2015) KCC2 function modulates in vitro ictogenesis. Neurobiol Dis 79:51-58.

Heinemann U, Lux HD, Gutnick MJ (1977) Extracellular free calcium and potassium during paroxsmal activity in the cerebral cortex of the cat. Exp Brain Res 27:237-243.

Hochman DW, Baraban SC, Owens JW, Schwartzkroin PA (1995) Dissociation of synchronization and excitability in furosemide blockade of epileptiform activity. Science 270:99-102.

Kahle KT, Rinehart J, Ring A, Gimenez I, Gamba G, Hebert SC, Lifton RP (2006) WNK protein kinases modulate cellular Cl- flux by altering the phosphorylation state of the $\mathrm{Na}-\mathrm{K}-\mathrm{Cl}$ and $\mathrm{K}-\mathrm{Cl}$ cotransporters. Physiology (Bethesda) 21:326-335.

Kahle KT, Staley KJ, Nahed BV, Gamba G, Hebert SC, Lifton RP, Mount DB (2008) Roles of the cation-chloride cotransporters in neurological disease. Nat Clin Pract Neurol 4:490-503.

Kahle KT, Deeb TZ, Puskarjov M, Silayeva L, Liang B, Kaila K, Moss SJ (2013) Modulation of neuronal activity by phosphorylation of the K-Cl cotransporter KCC2. Trends Neurosci 36:726-737.

Kahle KT, Khanna AR, Duan J, Staley KJ, Delpire E, Poduri A (2016) The KCC2 cotransporter and human epilepsy: getting excited about inhibition. Neuroscientist 22:555-562.

Khazipov R, Valeeva G, Khalilov I (2015) Depolarizing GABA and developmental epilepsies. CNS Neurosci Ther 21:83-91.

Korpi ER, Lüddens H (1997) Furosemide interactions with brain GABAA receptors. Br J Pharmacol 120:741-748.

Kuner T, Augustine GJ (2000) A genetically encoded ratiometric indicator for chloride: capturing chloride transients in cultured hippocampal neurons. Neuron 27:447-459.

Lillis KP, Kramer MA, Mertz J, Staley KJ, White JA (2012) Pyramidal cells accumulate chloride at seizure onset. Neurobiol Dis 47:358366.

Lux HD, Heinemann U (1978) lonic changes during experimentally induced seizure activity. Electroencephalogr Clin Neurophysiol Suppl (34):289-297.

Magloire V, Cornford J, Lieb A, Kullmann DM, Pavlov I (2019) KCC2 overexpression prevents the paradoxical seizure-promoting action of somatic inhibition. Nat Commun 10:1225. 
Melo Z, de Los HP, Cruz-Rangel S, Vázquez N, Bobadilla NA, Pasantes-Morales H, Alessi DR, Mercado A, Gamba G (2013) Nterminal serine dephosphorylation is required for $\mathrm{KCC} 3$ cotransporter full activation by cell swelling. J Biol Chem 288:3146831476.

Moore YE, Deeb TZ, Chadchankar H, Brandon NJ, Moss SJ (2018) Potentiating KCC2 activity is sufficient to limit the onset and severity of seizures. Proc Natl Acad Sci USA 115:10166-10171.

Mtchedlishvili Z, Kapur J (2006) High-affinity, slowly desensitizing GABAA receptors mediate tonic inhibition in hippocampal dentate granule cells. Mol Pharmacol 69:564-575.

Nardou R, Ben-Ari Y, Khalilov I (2009) Bumetanide, an NKCC1 antagonist, does not prevent formation of epileptogenic focus but blocks epileptic focus seizures in immature rat hippocampus. $J$ Neurophysiol 101:2878-2888.

Nardou R, Yamamoto S, Chazal G, Bhar A, Ferrand N, Dulac O, BenAri Y, Khalilov I (2011) Neuronal chloride accumulation and excitatory GABA underlie aggravation of neonatal epileptiform activities by phenobarbital. Brain 134:987-1002.

Painter MJ, Scher MS, Stein AD, Armatti S, Wang Z, Gardiner JC, Paneth N, Minnigh B, Alvin J (1999) Phenobarbital compared with phenytoin for the treatment of neonatal seizures. $\mathrm{N}$ Engl $\mathrm{J}$ Med 341:485-489.

Pallud J, Le Van QM, Bielle F, Pellegrino C, Varlet P, Cresto N, Dieme MJ, Baulac M, Duyckaerts C, Kourdougli N, Chazal G, Devaux B, Rivera C, Miles R, Capelle L, Huberfeld G (2014) Cortical GABAergic excitation contributes to epileptic activities around human glioma. Sci Transl Med 6:244ra89.

Pisella LI, Gaiarsa JL, Diabira D, Zhang J, Khalilov I, Duan J, Kahle KT, Medina I (2019) Impaired regulation of KCC2 phosphorylation leads to neuronal network dysfunction and neurodevelopmental pathology. Sci Signal 12:eaay0300.

Pond BB, Berglund K, Kuner T, Feng G, Augustine GJ, SchwartzBloom RD (2006) The chloride transporter $\mathrm{Na}(+)-\mathrm{K}(+)$-Cl- cotransporter isoform-1 contributes to intracellular chloride increases after in vitro ischemia. J Neurosci 26:1396-1406.
Roseth S, Fykse EM, Fonnum F (1995) Uptake of L-glutamate into rat brain synaptic vesicles: effect of inhibitors that bind specifically to the glutamate transporter. J Neurochem 65:96-103.

Sivakumaran S, Maguire J (2016) Bumetanide reduces seizure progression and the development of pharmacoresistant status epilepticus. Epilepsia 57:222-232.

Sivakumaran S, Cardarelli RA, Maguire J, Kelley MR, Silayeva L, Morrow DH, Mukherjee J, Moore YE, Mather RJ, Duggan ME, Brandon NJ, Dunlop J, Zicha S, Moss SJ, Deeb TZ (2015) Selective inhibition of KCC2 leads to hyperexcitability and epileptiform discharges in hippocampal slices and in vivo. J Neurosci 35:8291-8296.

Staley KJ, Proctor WR (1999) Modulation of mammalian dendritic GABA(A) receptor function by the kinetics of $\mathrm{Cl}$ - and $\mathrm{HCO} 3$ transport. J Physiol 519 [Pt 3]:693-712.

Stein V, Hermans-Borgmeyer I, Jentsch TJ, Hübner CA (2004) Expression of the $\mathrm{KCl}$ cotransporter $\mathrm{KCC} 2$ parallels neuronal maturation and the emergence of low intracellular chloride. J Comp Neurol 468:57-64.

Takayama C, Inoue Y (2010) Developmental localization of potassium chloride co-transporter 2 (KCC2), GABA and vesicular GABA transporter (VGAT) in the postnatal mouse somatosensory cortex. Neurosci Res 67:137-148.

van den Pol AN, Obrietan K, Chen G (1996) Excitatory actions of GABA after neuronal trauma. J Neurosci 16:4283-4292.

Vargova L, Jendelova P, Chvatal A, Sykova E (2001) Glutamate, NMDA, and AMPA induced changes in extracellular space volume and tortuosity in the rat spinal cord. J Cereb Blood Flow Metab 21:1077-1089.

Viitanen T, Ruusuvuori E, Kaila K, Voipio J (2010) The K+-Cl cotransporter KCC2 promotes GABAergic excitation in the mature rat hippocampus. J Physiol 588:1527-1540.

Watanabe M, Zhang J, Mansuri MS, Duan J, Karimy JK, Delpire E, Alper SL, Lifton RP, Fukuda A, Kahle KT (2019) Developmentally regulated KCC2 phosphorylation is essential for dynamic GABAmediated inhibition and survival. Sci Signal 12:eaaw9315. 